\title{
EL FENÓMENO FUNERARIO EN LA EDAD DEL HIERRO DEL CANTÁBRICO. UN NUEVO ESPACIO RITUAL EN LA NECRÓPOLIS DE MONTE BERNORIO (CAMPAÑAS DE EXCAVACIÓN DE 2007 Y 2008)
}

\author{
THE FUNERARY PHENOMENON IN THE CANTABRIAN IRON AGE. A NEW RITUAL SPACE IN THE \\ NECROPOLIS OF MONTE BERNORIO (EXCAVATIONS FROM 2007 AND 2008)
}

JESÚS F. TORRES-MARTÍNEZ (KECHU)

Instituto Monte Bernorio de Estudios de la Antigüedad del Cantábrico (IMBEAC)

Universidad Complutense de Madrid ketxutorres@yahoo.com http://orcid.org/0000-0003-4714-1567

ÁNGEL FUENTES

Universidad Autónoma de Madrid angel.fuentes@uam.es http://orcid.org/0000-0002-5314-8063

SANTIAGO D. DOMÍNGUEZ SOLERA

Instituto Monte Bernorio de Estudios de la Antigüedad del Cantábrico (IMBEAC)

Universidad Complutense de Madrid cazadorrecolector@hotmail.com http://orcid.org/0000-0002-0751-5336

ANA RODRÍGUEZ TRIGO anuska.art24@gmail.com http://orcid.org/0000-0003-1562-4919
CHRISTIAN HAMANN

Leibniz-Laboratory for Radiometric Dating and Isotope Research

University of Kiel chamann@1eibniz.uni-kiel.de http://orcid.org/0000-0001-7638-8230

\section{RICARDO FERNANDES}

Department of Archaeology Max Planck Institute for the Science of Human History McDonald Institute for Archaeological Research

University of Cambridge rf385@cam.ac.uk http://orcid.org/0000-0003-2258-3262

ANTXOKA MARTÍNEZ VELASCO

Instituto Monte Bernorio de Estudios de la Antigüedad del Cantábrico (IMBEAC) Sociedad de Ciencias Aranzadi antxokagaldakao@hotmail.com http://orcid.org/0000-0003-2248-3763

ALIS SERNA GANCEDO

Instituto Monte Bernorio de Estudios de la Antigüedad del Cantábrico (IMBEAC) alixserna@gmail.com http://orcid.org/0000-0002-9892-1849

JUAN M. SOBREMAZAS MARTÍNEZ

Instituto Monte Bernorio de Estudios de la Antigüedad del Cantábrico (IMBEAC) ambatos_ambatikun@hotmail.com http://orcid.org/0000-0003-1901-1140

Recepción: 31-05-2017

Aceptación: 10-10-2017 


\section{Resumen}

La necrópolis del oppidum de Monte Bernorio fue uno de los primeros cementerios de la Edad del Hierro excavados en España. No obstante, la atención a los excepcionales materiales metálicos descubiertos en ella, unido a la escasez de restos relacionados con los rituales, ha impedido conocer hasta este momento qué tipo de ceremonias funerarias se desarrollaron en ella. En este trabajo se presentan los diversos estudios y análisis realizados sobre las evidencias recuperadas en las excavaciones de las campañas de 2007 y 2008, así como los resultados obtenidos y las interpretaciones que de estos hemos realizado. El resultado es la identificación de un tipo de ritual que invisibiliza los restos y que implica un uso diferente de los espacios funerarios.

Palabras clave. Edad del Hierro; oppidum; necrópolis; muestras; análisis; rituales funerarios; invisibilidad.

\begin{abstract}
The necropolis of the oppidum of Monte Bernorio was one of the first Iron Age cemeteries excavated in Spain. However, the focus of previous studies on the exceptional metal objects discovered, plus the scarcity of human remains, prevented us from establishing the type of funerary ceremonies that took place at the site. This work presents the interpretation of the outcome of the different studies and analyses made on the material evidence recovered during the excavations carried out in 2007 and 2008. As a result, a funerary ritual that obscures the presence of human remains and implies an different use of funerary spaces has been identified.
\end{abstract}

Keywords. Iron Age; oppidum; necropolis; samples; analysis; funerary rituals; invisibility.
La zona arqueológica de Monte Bernorio se sitúa en el municipio de Pomar de Valdivia (Palencia) (Fig. 1) y actualmente es uno de los yacimientos más importantes de la Protohistoria española. Comprende varios yacimientos de distintas épocas, pero en lo que a este trabajo se refiere, nos vamos a centrar en el oppidum de la Edad del Hierro y sus espacios asociados, en concreto en los espacios rituales con prácticas funerarias. El núcleo del Bernorio es conocido arqueológicamente desde las excavaciones de R. Moro en 1890 $\mathrm{y}$, posteriormente, gracias a las excavaciones de J. San Valero Aparisi de 1943, 1944 y 1959. En el año 2004

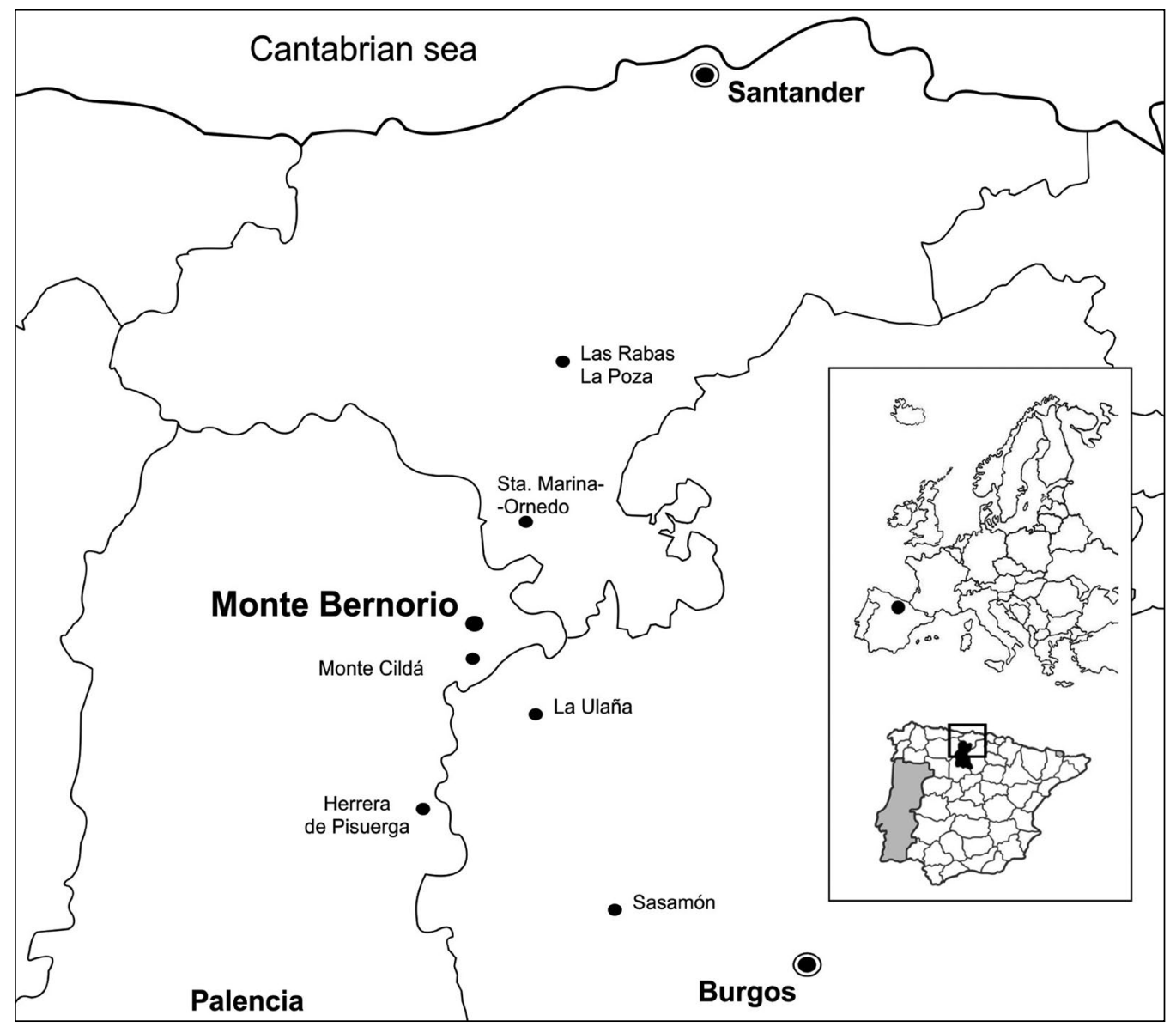

Figura 1: Situación del oppidum de Monte Bernorio en el norte de la Península Ibérica y yacimientos protohistóricos más destacados en sus inmediaciones (Infografía de A. Martínez Velasco y Equipo Bernorio IMBEAC). 
se inició el actual proyecto de investigación. Existe ya una bibliografía que permite acercarse al conocimiento del oppidum, su estructura, su cultura material y otros aspectos destacados (San Valero, 1944, 1959; Torres-Martínez, Martínez y de Luis, 2012; TorresMartínez, Martínez y Serna, 2013; Torres-Martínez, Martínez y Vacas, 2015; Torres Martínez, FernándezGötz y Sobremazas, 2016; Torres-Martínez et al., 2016a; 2016b; Torres-Martínez, Martínez y Luis, 2016). No obstante, los trabajos de prospección y excavación realizados en la necrópolis permanecen prácticamente inéditos, por lo que vamos a dar a conocer una parte de ellos, los realizados por este equipo entre los años 2004 y 2008 (Torres-Martínez, Martínez y Serna, 2013: 67-71).

\section{LA NECRÓPOLIS DE MONTE BERNORIO (1890-2004)}

La necrópolis de Monte Bernorio (Villarén de Valdivia, Palencia) fue excavada por primera vez en 1890 por Romualdo Moro (1891), capataz de excavaciones arqueológicas del Marqués de Comillas. Éste realizaba una campaña de «exploraciones arqueológicas» en el norte de Palencia en la que excavó en varios yacimientos de la misma comarca y en el Bernorio, cuya cima era conocida como lugar de ruinas antiguas. Estas exploraciones y excavaciones eran, en realidad, rebuscas para alimentar la colección de materiales arqueológicos del Marqués, costumbre extendida entre los aristócratas de esa época.

En el Bernorio excavó en el interior del oppidum (con muy poco éxito para sus expectativas) pero recibió noticias de un lugar en el que aparecían objetos metálicos antiguos. Desplazó a esa zona de las laderas de la cima del Bernorio a su cuadrilla de jornaleros y realizó unas cuantas zanjas hasta que dio con una zona en la que aparecieron una serie de materiales antiguos de estilo desconocido por aquel entonces (Moro, 1891: 432-437).

Los materiales aparecidos en la necrópolis del Bernorio, y muy especialmente los puñales Monte Bernorio, fueron una novedad sorprendente por su tipo de diseño y sus remates de discos que eran desconocidos en el resto de Europa. Este tipo de puñales fueron fechados en los momentos finales del siglo IV y el siglo III a.C. (Cabré y Cabré 1933: 42-43). Los materiales extraídos de la necrópolis de Monte Bernorio pasaron a formar parte de la Colección del Marqués de Comillas ${ }^{1}$ (Sanz et al., 1991: 79-80) Dada la originalidad de

\footnotetext{
1. Esta colección fue adquirida por la Fundación Eugenio Fontaneda y se encuentra actualmente en la «Colección Eugenio Fontaneda» depositada en el Castillo-Museo de Ampudia (Palencia). El Instituto Monte Bernorio de Estudios de la Antigüedad del Cantábrico (IMBEAC) está desarrollando un estudio de esta colección de objetos arqueológicos desde el año 2016.
}

su diseño y sus estilos decorativos este tipo de puñales han sido investigados por numerosos investigadores de la Protohistoria española y (Cabré, 1920; 1931: 222-241, Fig. 4, Lams. I, IX, X, XI; Cabré y Cabré, 1933; Navarro, 1939: 164-172; San Valero, 1944; 1959; Schüle, 1969a; 1969b; Griñó, 1987; 1989a; 1989b; Barril 1995a: 408; 1995b; 1999: 46-51; Alonso et al., 1999; Filloy, 2000). Los estudios más completos sobre este tipo de puñales han sido realizados por C. Sanz Mínguez que recoge los hallazgos de este tipo de puñal en el centro y norte de la Península Ibérica y en el sur de Francia. (Sanz Mínguez, 1986: 25-31 y Figs. 1-5, 1990: 172-175, 176-179, 180-185 y Figs. 2, 3 ). Además, ha desarrollado una serie de estudios que han servido para establecer su evolución cronológica (Sanz Mínguez, 1986: 38-40 y Fig. 6; 1990: 175-176, 179-180, 184-187, y Fig. 1).

Estos materiales metálicos, y otros procedentes de la necrópolis de Miraveche, caracterizan el área central de un conjunto crono-cultural denominado como «Miraveche-Monte Bernorio». Éste define la cultura metalúrgica del momento de transición entre la Primera y la Segunda Edad del Hierro en la zona central del norte de la Península Ibérica (Cabré, 1931, 222-241, Fig. 4, Láms. I, IX, X, XI; Cabré y Cabré, 1933, 3945, Láms. VII-X; Cabré y Baquedano, 1997, 249-251; Sanz 1986: 25; 1990: 170; 1991; Peralta 2003: 56-57, 62). Este verdadero horizonte cultural define un estilo original y característico en las producciones metalúrgicas que supone la consolidación de la metalurgia del hierro y de estas sociedades célticas de cultura agroganadera y guerrera.

En 1943 J. San Valero Aparisi (1944: 28-33; 1959: 8-9) excava de nuevo en la cima de Monte Bernorio y establece que se trata sin duda de un castro. En esta primera campaña realiza indagaciones e interviene en la misma zona en la que excavó R. Moro en 1890, lo que para él parece ser una prioridad. Tras mucho esfuerzo, a 1,5 m de profundidad, localiza lo que describe como «seis u ocho» túmulos que, al excavarlos, comprueba que varios de ellos están alterados por las rebuscas de R. Moro. Aunque logra encontrar otras estructuras intactas, estas no contienen «materiales significativos», y sólo en dos de los túmulos logró encontrar ajuares metálicos. J. San Valero documenta con dibujos y fotografías las estructuras y los ajuares, publicando esta información en el avance a una memoria de las excavaciones $^{2}$, publicada en 1944.

Los «túmulos» que describe J. San Valero son amontonamientos de piedras de forma más o menos ordenada formando una estructura tumuliforme de tamaño mediano y pequeño. Uno de estos, que fue encontrado intacto, J. San Valero lo describe como varias piedras dispuestas de modo tosco alrededor de

\footnotetext{
2. Esta memoria de sus trabajos, que llego a estar redactada y entregada, quedó inédita; nunca llegó a ser publicada y se da actualmente por perdida.
} 
la tumba y cubierto todo por una losa de mayor tamaño formando un amontonamiento. A este tipo de estructuras las denomina «mesas de roca» y en su interior se encontraba el ajuar. En ambas estructuras el ajuar es uniforme y estaba compuesto por un puñal de tipo Monte Bernorio, puntas de lanza y tahalíes. No hay restos de recipientes cerámicos y se encontraron apenas un par de esquirlas de hueso cremado. Hay que llamar la atención sobre el hecho de que alrededor de las estructuras aparecieron una gran cantidad de fragmentos de material metálico quemado y muy fragmentado (San Valero 1944, 28-33, 45-47, Lams. VI y VII).

Estas estructuras «tumulares» se asentaba en la base caliza del suelo y, en apariencia, el material que lo cubría sería sedimento procedente del tell generado en el castro. Sin embargo es muy probable que una parte de este sedimento, lleno de fragmentos de objetos metálicos de pequeño tamaño, formara parte del contenido y de una posible cubierta de tierra de los túmulos. Ésta cubierta de tierra se habría ido deteriorado y erosionado con el paso del tiempo (en época protohistórica) hasta disolverse y formar un nivel de tierra más o menos homogéneo. Este nivel fue cubierto, a su vez, con los aportes de tierra del castro por escorrentía y por el suelo generado por la descomposición vegetal y los depósitos de polvo.

\section{LAS NECRÓPOLIS DE MONTE BERNORIO (2004-2008)}

En la campaña del año 2004 se realizaron una serie de prospecciones minuciosas en todo el perímetro del oppidum. Esto sirvió para revisar su estructura defensiva y situar el trazado de la muralla por su lado sur, cuya existencia se mantenía en su mayor parte inédita. Precisamente en esta ladera sur se realizaron minuciosas prospecciones en las terrazas en las que se indicaba estaba el área de necrópolis, aunque de modo demasiado vago, en la publicación de J. San Valero (1960: 105-106, Fig. 1). Los resultados de estos trabajos nos indicaban una escasa presencia de materiales en las terrazas agrícolas, pero con presencia de algunos indicadores significativos como son fragmentos de cerámicas y algunos muy pequeños fragmentos de hueso cremado. Con estos resultados, y teniendo en cuenta las indicaciones de J. San Valero sobre la profundidad

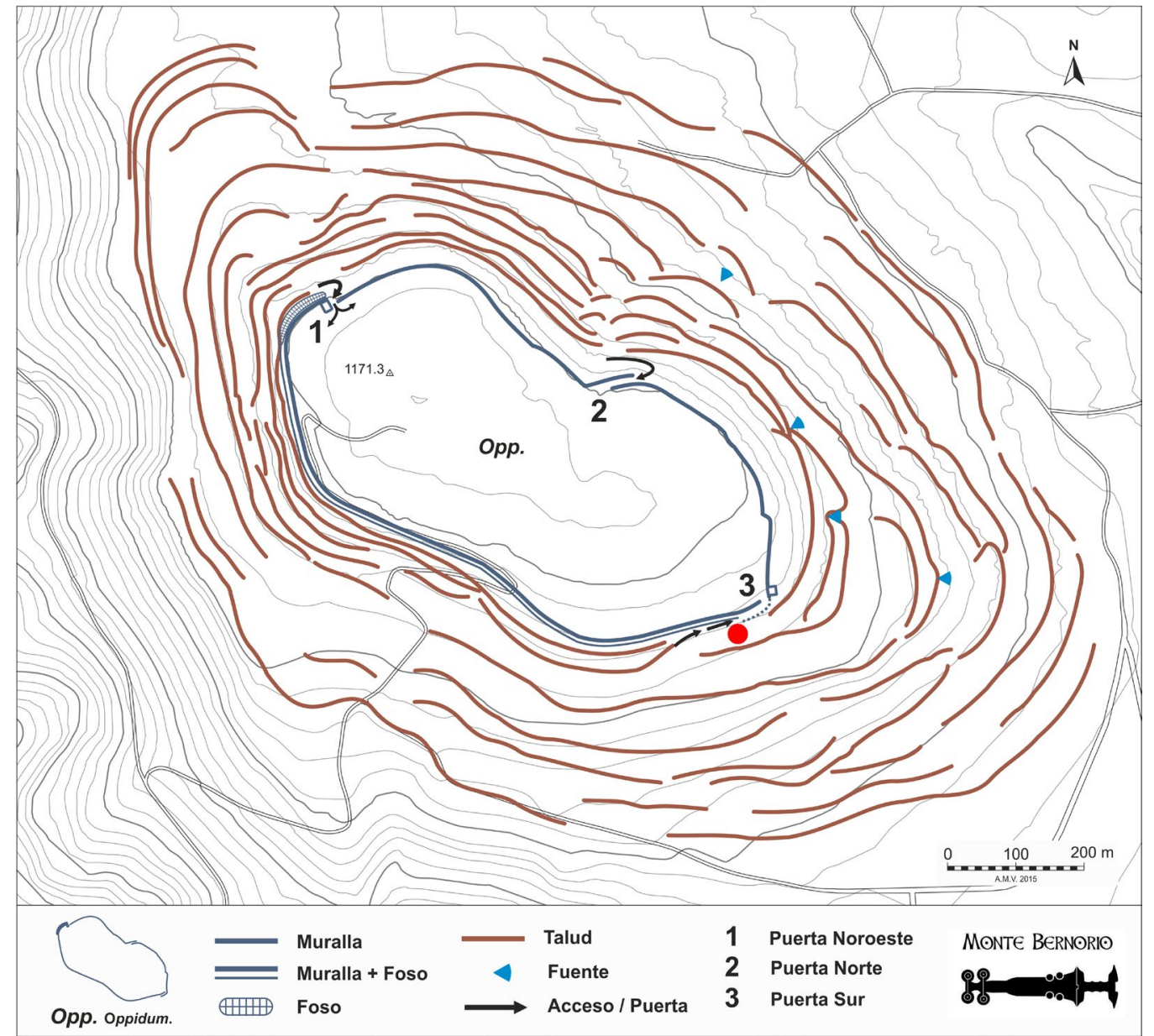

Figura 2: Plano del oppidum de Monte Bernorio con su sistema defensivo de tipo «Complejo». El espacio de necrópolis excavado en las campañas de 2007-2008 está señalizado con un punto al lado de la puerta sur, integrado en el sistema de multivallado (Infografía de Equipo Bernorio IMBEAC y A. Martínez Velasco). 


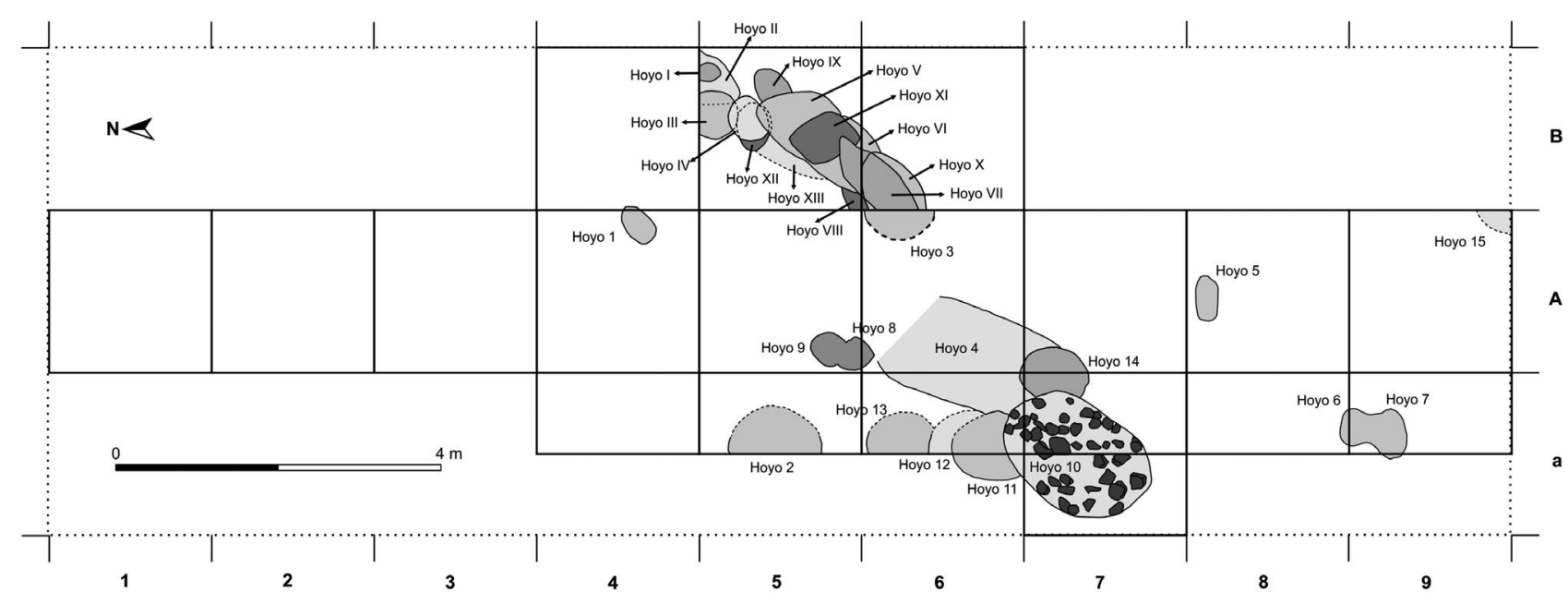

Figura 3: Bernorio, Área 7, Necrópolis. Plano del transect excavado durante las excavaciones de 2007 y 2008 (Infografía de Equipo Bernorio IMBEAC y A. Martínez Velasco).

a la que aparecieron los restos localizados por él, llegamos a la conclusión de que es muy posible que en la ladera sur del Bernorio, y a una considerable profundidad, hubiese varias zonas que hubieran podido tener un uso ritual $\mathrm{y} / \mathrm{o}$ funerario.

En estas prospecciones se identificó una muy ligera elevación en una porción de terreno explotado agrícolamente con forma lenticular y con una concentración de materiales arqueológicos en superficie: cerámicas torneadas de tipo celtibérico de pastas beige y anaranjadas principalmente y algún fragmento de gran calidad de tipo rojizo, así como fragmentos de hueso de pequeño tamaño.

En la campaña de 2006 se repitió la prospección minuciosa de este y otros espacios. Un informante nos comunicó confidencialmente que había observado cómo esa área en concreto había sido objeto de atención por parte de expoliadores de modo reiterado y que era denominada como «El Túmulo». Otro informante nos refirió que había escuchado comentarios sobre cómo en ese lugar se habían sustraído piezas metálicas excelentes, entre ellas puntas de lanza y un torque (o fragmentos de una pieza similar) que decían era de oro. También le habían comentado un hecho llamativo para él, que un expoliador se había apropiado de grandes fragmentos de una cerámica torneada de gran calidad y bellamente decorada (de tipo celtibérica), lo que no es habitual en el modus operandi de este tipo de sujetos.

Una vez revisadas todas estas evidencias, y conociendo estas preocupantes informaciones, decidimos realizar un sondeo en dicho espacio (Fig. 2). Para ello nos pusimos de acuerdo con la persona que tenía en explotación esa finca y solicitamos su permiso para realizar dicha intervención una vez recogida la cosecha, a lo que amablemente accedió. Así, esta zona, prospectada desde 2004, finalmente se excavó en dos campañas sucesivas, en los años 2007 y 2008, denominándose como Área 7.

\section{CAMPAÑAS DE EXCAVACIÓN}

\section{CAMPaÑa de 2007}

Se marcó un transect en dirección N-S, de $2 \times 10 \mathrm{~m}$ (Fig. 3) El área intervenida se encontraba en parte fuera del sembrado, pero con la mayor parte en la tierra de labor. Una vez retirados los arbustos del talud, se procedió a la limpieza del sustrato vegetal y a retirar el sistema reticular que había debajo. Tras esto, aunque en superficie se apreciaba una acumulación de tierras en forma de túmulo, no fue posible identificar un perímetro de piedra o cualquier otra estructura que lo delimitara.

Se excavaron los cuadros marcados retirando el paquete de tierras alteradas por los trabajos agrícolas, de unos $30 \mathrm{~cm}$ de potencia. En el procesado y criba de tierras de los niveles más superficiales ${ }^{3}$ se recuperaron galbos cerámicos similares a los obtenidos en las prospecciones. Además, se obtuvo una cantidad relativamente abundante de restos de objetos metálicos: la punta de un proyectil grande y puntiagudo de hierro, lo que parece un fragmento de punta de flecha, fragmentos de fíbula, clavos, chapitas de bronce, etc. (Fig. 4). Muchos de estos objetos rescatados en los niveles más superficiales serían restos de elementos de armamento y de adornos. No podemos descartar que algunos de ellos pudieran haber pertenecido al contenido de los hoyos destruidos y removidos por el arado y/o por procesos postdeposicionales. Pero, en general, pueden ser relacionados con el momento de asalto y destrucción del núcleo en el siglo I a. C. (Torres-Martínez, Martínez, Pérez 2012; Torres-Martínez, Martínez, Pérez 2013; Torres-Martínez 2015).

3. En los niveles denominados como la UEs 1, 2 (alterados por el arado) y 3, nivel arqueológico de la Edad del Hierro, conteniendo el resto de las distintas unidades estratigráficas. 
1)

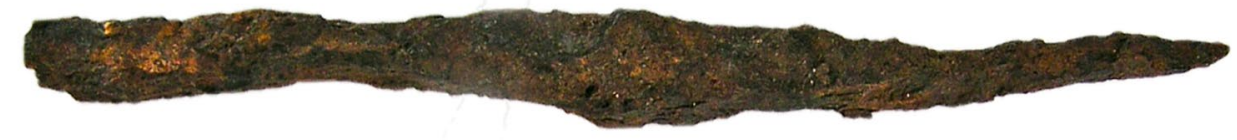

2)

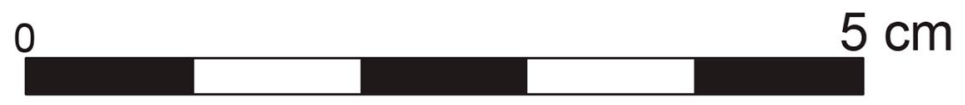

Figura 4: Materiales militares romanos, puntas de proyectiles. 1. Punta de pilum o similar. 2. Punta de flecha (Fotgrafía de Equipo Bernorio e Infografía de D. Vacas Madrid IMBEAC).

Una vez limpiados los niveles superficiales y el sustrato alterado por los trabajos agrícolas, se detectaron una serie de manchas más oscuras que contrastaban radicalmente con los limos amarillos del nivel geológico (Fig. 5). Por este motivo se decidió ampliar el sondeo en dirección sur y oeste para abarcar de modo suficiente aquellas zonas en las que existían indicios de estructuras arqueológicas.

Cada una de las manchas detectadas se identificó como un posible hoyo y se le asignó un número identificativo. Se identificaron hasta 15 hoyos de diferentes tamaños con formas circulares u ovoides. Los Hoyos 4 y 10 resultaron ser los más grandes, con casi $2 \mathrm{~m}$ de diámetro aproximado, pero el resto no alcanzaban los $0,5 \mathrm{~m}$. En la zona media del sondeo se identificó una concentración de hoyos que se superponen e invaden

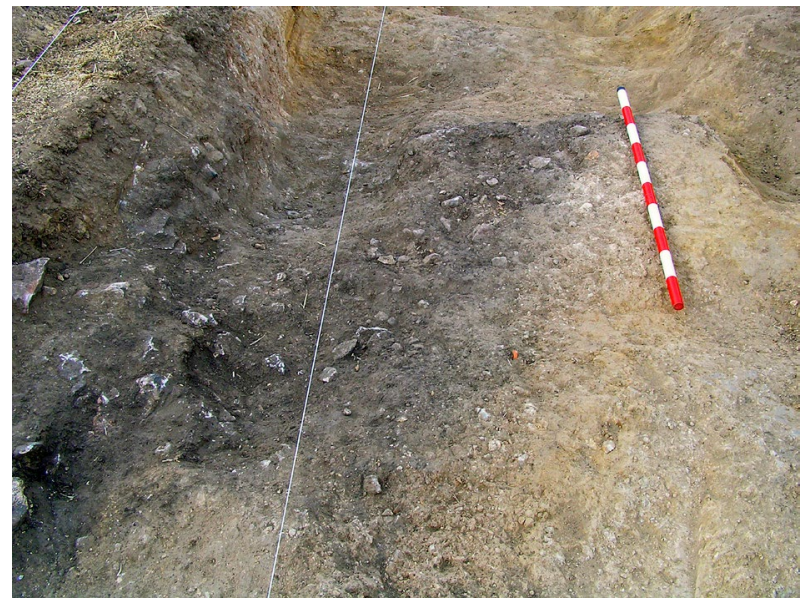

Figura 5: Bernorio, Área 7, Necrópolis. Vista de la excavación del 2007 con las manchas negruzcas de los hoyos localizados (Fotografías Equipo Bernorio IMBEAC). unos a otros, habiendo sido posible reconstruir la secuencia en la que fueron construidos. El orden de las estructuras, de la más reciente a la más antigua, es: 10, 14-11, 12, 4-13, 9 y 8 . Sólo cuatro hoyos de pequeño tamaño quedaban fuera de esta concentración. El resto de hoyos $(1,2,3,5,6 / 7)$ no están relacionados y aparecían dispersos por las inmediaciones. Los números 6 y 7 sí se superponían, cortándose entre ellos, pero fue imposible distinguir cuál era el anterior y cuál el posterior dado que el relleno de ambos era idéntico y no había otros indicios que permitieran un diagnóstico al respecto (Fig. 6). Hemos establecido una tipología de los hoyos y cubetas con tres patrones principales:

- 1. Los hoyos más pequeños (con menos de $50 \mathrm{~cm}$ de diámetro aproximado), que han sido excavados directamente sobre el nivel geológico y que no se superponen a ningún otro. Son los números 1, 3, 5, $6,7,8$ y 9 .

- 2. Los hoyos más grandes (de más de $50 \mathrm{~cm}$ de diámetro aproximado) que estarían encima, solapándose a los más pequeños y conformando el conjunto central. Son los números $2,4,11,12,13$, 14.

- 3. Los hoyos con cubierta pétrea, formando una muy pequeña estructura tumular: hoyos 4, 8-9, 10 .

Los hoyos se excavaron individualizadamente y de forma cuidadosa, cribando sus contenidos y recogiendo todos los restos recuperados. Todos los hoyos, sin excepción, tenían un relleno compuesto por tierras de aspecto ceniciento con abundantes microcarbones y restos de madera carbonizada. Se recogieron del interior de algunos de los hoyos varias muestras de tierra y de carbón vegetal para su análisis y para obtener dataciones radiocarbónicas y realizar análisis de 


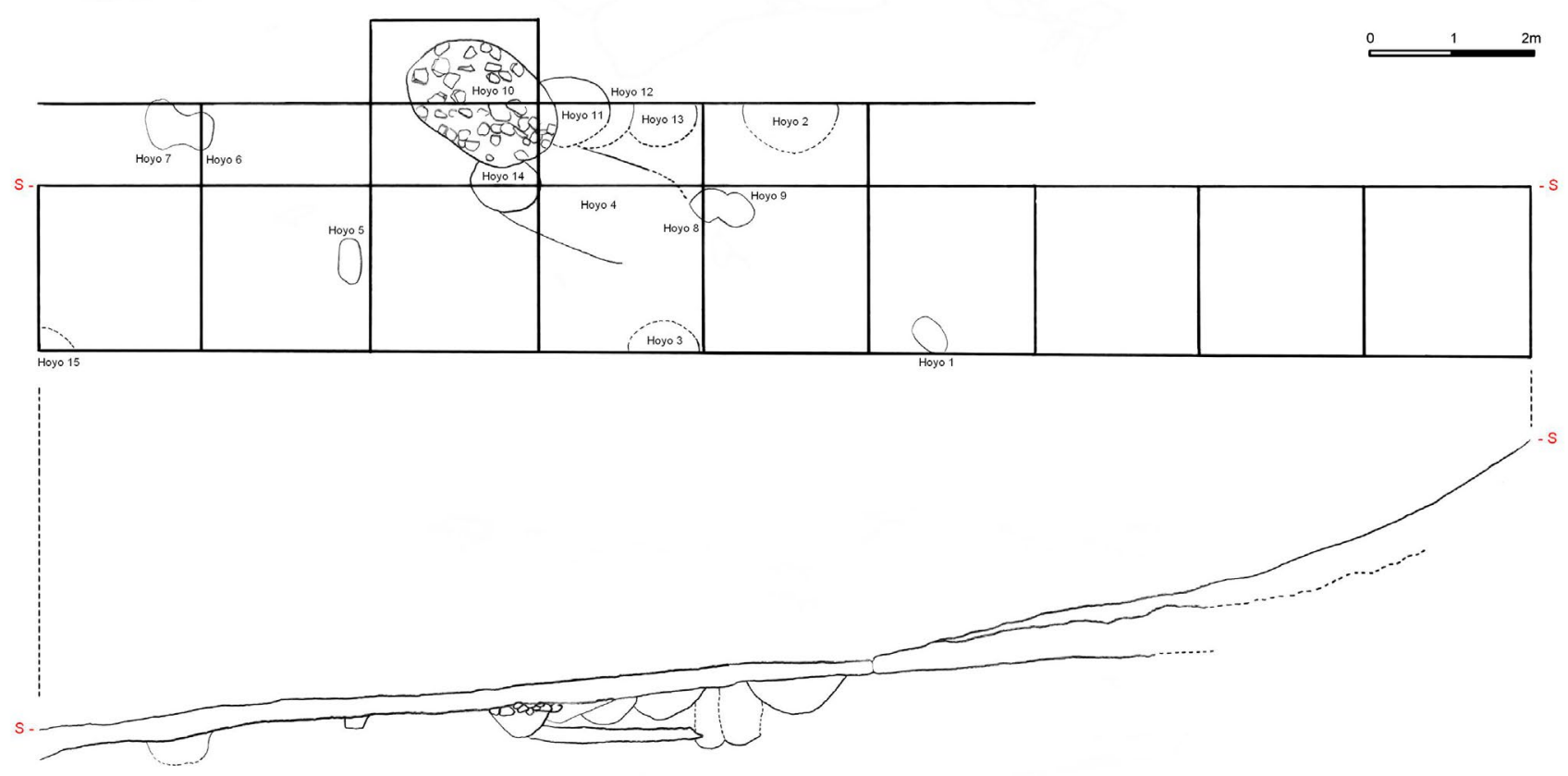

Figura 6: Bernorio, Área 7, Necrópolis. Plano con planta y perfil del transect realizado en la campaña del 2007 con los hoyos excavados (Infografía de Equipo Bernorio y S. Domínguez Solera y D. Vacas Madrid IMBEAC).

osteología antropológica ${ }^{4}$. El Hoyo 10, el de mayor tamaño y el realizado cronológicamente en el momento más reciente del conjunto central, estaba recubierto de un tapón de piedras y tenía un relleno en el que estaban contenidos todos los materiales depositados (Fig. 7). En los hoyos 4, 8-9 se detectó también presencia de piedras a modo de cubierta del depósito.

En lo que se refiere al relleno de los hoyos, en general el material más abundante era el hueso animal fragmentado: suido doméstico y salvaje (Sus scrofa), ovicápridos (Ovis aries/Capra hircus), vaca (Bos taurus) y ciervo (Cervus elaphus). También se identificaron algunos restos óseos, los de menor tamaño, quemados y cremados que pensábamos podían corresponder (al menos una parte de ellos) a restos humanos. Por debajo en porcentaje sobre el volumen total, tenemos representada la cerámica, tanto modelada como torneada. Abundan los restos de vasijas de pequeño y mediano tamaño (algunas probablemente cuencos pequeños) con ausencia de grandes recipientes. Algunos de los fragmentos de cerámica torneada están decorados con pintura (rayas paralelas y círculos concéntricos). Todos los galbos aparecen muy fragmentados, en trozos muy pequeños, pero se observa que están muy poco rodados, lo que elimina la posibilidad de que llegasen al interior de los hoyos como producto

4. Se tomaron las muestras de los hoyos cuyo relleno parecía más preservado y donde consideramos que era más difícil la posibilidad de mezclas accidentales con el contenido de otras unidades estratigráficas. Para contrastar y cotejar las muestras se ha recogido también una bolsa de tierra de superficie del nivel agrícola y otra de la ladera. En la fecha de publicación de este trabajo se han realizado la práctica totalidad de los analisis de restos propuestos en un principio. del arrastre o remociones del terreno. También han sido recuperados restos de goterones de metal fundido (Cobre/bronce) de pequeño tamaño.

En el interior de la mayoría de los hoyos se recuperaron restos de objetos metálicos con representación de, al menos, un objeto de bronce; todos con claros signos de haber sido quemados. En el Hoyo 3 un fragmento de chapa de hierro perforada y un remate broncíneo cónico (probablemente de una fíbula); en el Hoyo 4 un puente de fíbula y otros restos metálicos no identificables; en el Hoyo 6 un fragmento de chapa de hierro perforada con remaches de bronce y una tachuela de caliga (en la superficie); en el Hoyo 8 cuentas de collar de bronce y un fragmento de chapita broncínea; en el Hoyo 11 una tachuela de caliga y pequeños fragmentos de bronce. Destaca especialmente

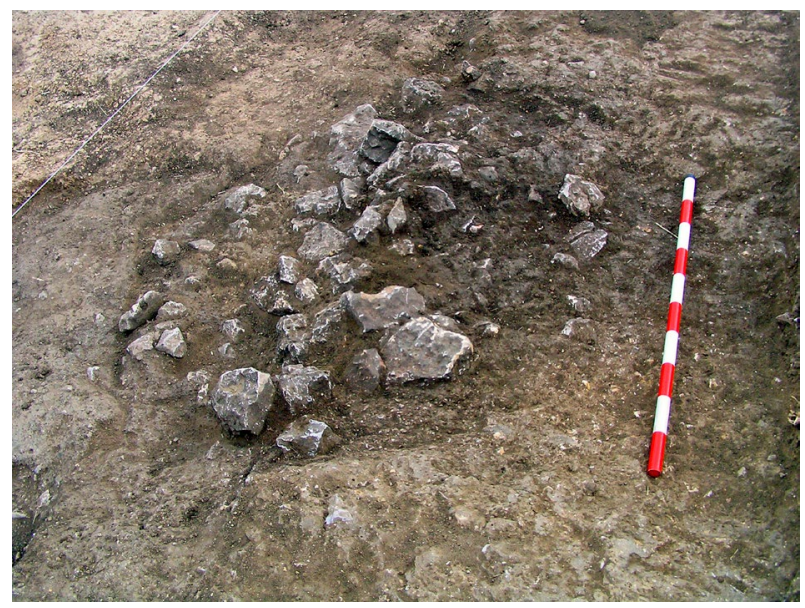

Figura 7: Bernorio, Área 7, Necrópolis. Vista del Hoyo 10 en la excavación del 2007 con la cubierta de piedra (Fotografías Equipo Bernorio IMBEAC). 


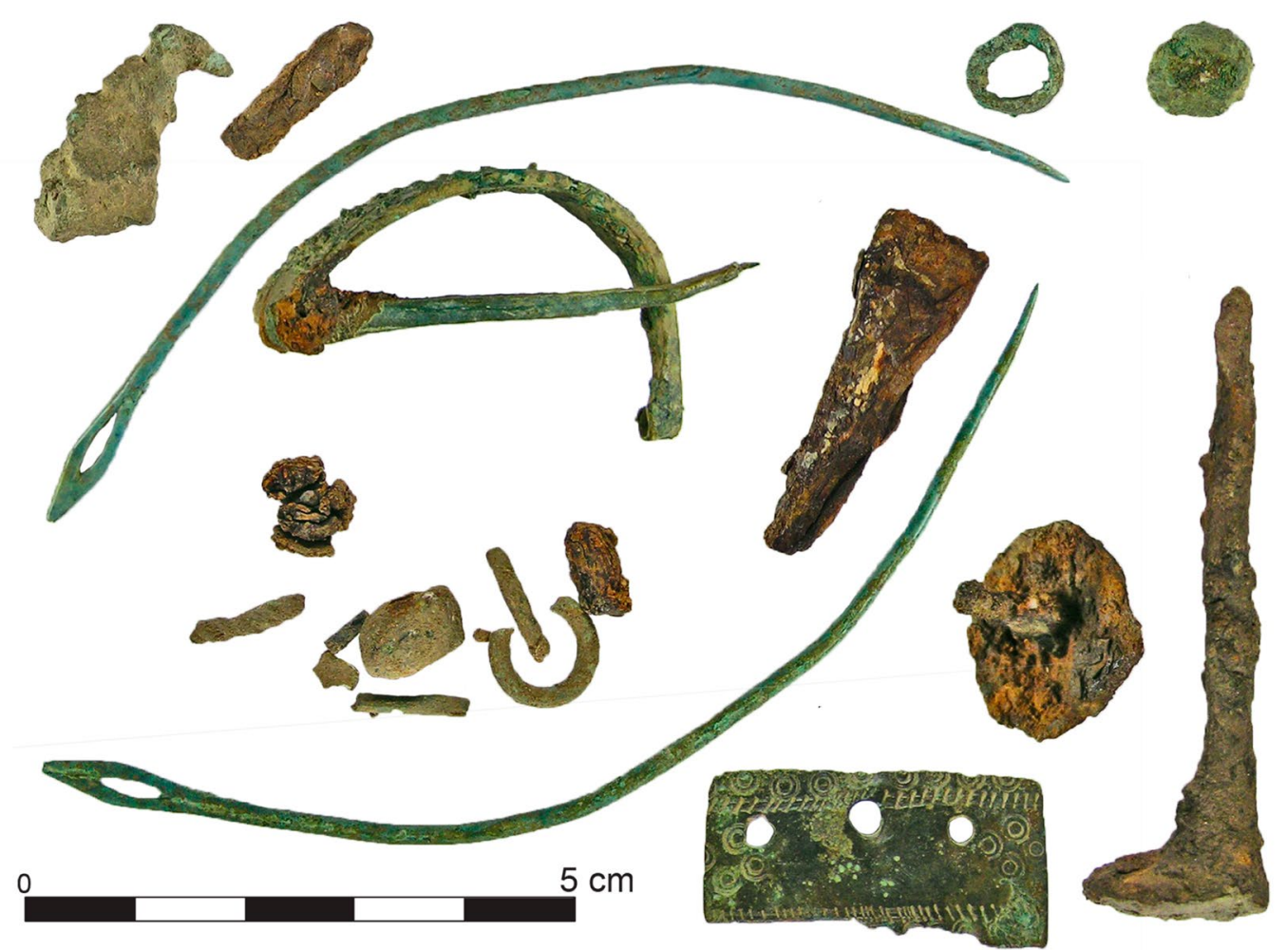

Figura 8A: Bernorio, Area 7, Necrópolis, Campaña 2007. Conjunto de ajuar metálico del Hoyo 10 (Fotografías Equipo Bernorio, Infografía de D. Vacas-Madrid IMBEAC).

el Hoyo 10 con tachuelas de caliga, un fragmento de placa de hebilla de cinturón, fragmentos de un adorno no identificable de bronce, una anillita de un posible colgante de bronce, una especie de gubia, una tachuela decorativa para elemento de cuero (tal vez de cinturón) y un fragmento del cierre/puente de una fíbula de bronce y una fíbula de tipo Alesia prácticamente completa (Fig. 8A).
Esta fíbula de tipo Alesia ha sido identificada como del tipo 8.2a de Erice (1995). La cronología aceptada generalmente para este tipo va desde mediados del s. I. a.C. hasta el cambio de Era pudiendo estar en uso en los primeros años del s. I. d.C., pero el periodo de máxima vigencia se sitúa a mediados del s. I. a.C. Sin embargo, algunos autores hacen retroceder la cronología de este tipo de fíbulas hasta inicios del siglo I a.C.
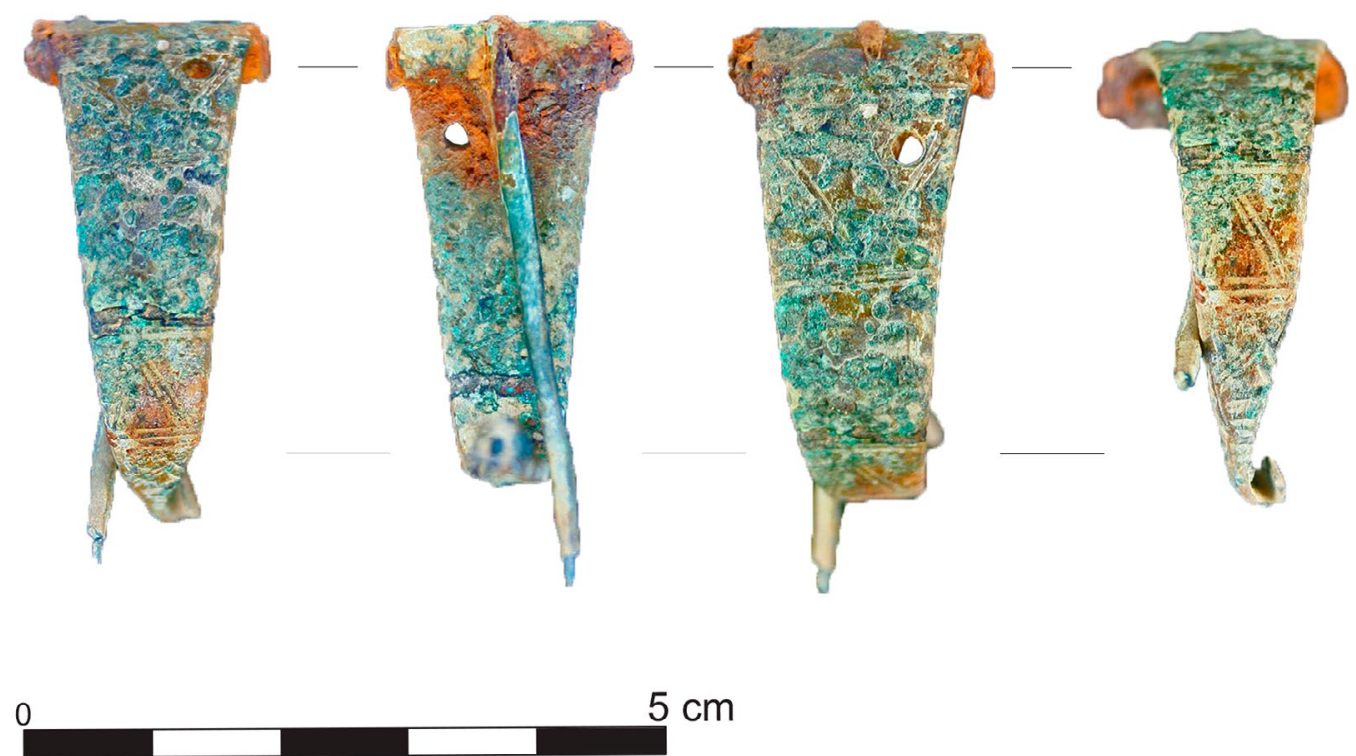

Figura 8B: Bernorio, Área 7, Necrópolis, Campaña 2007. Conjunto de vistas de detalle de la Fíbula de tipo Alesia recuperada en el Hoyo 10 (Fotografías Equipo Bernorio, Infografía de D. Vacas-Madrid IMBEAC). 


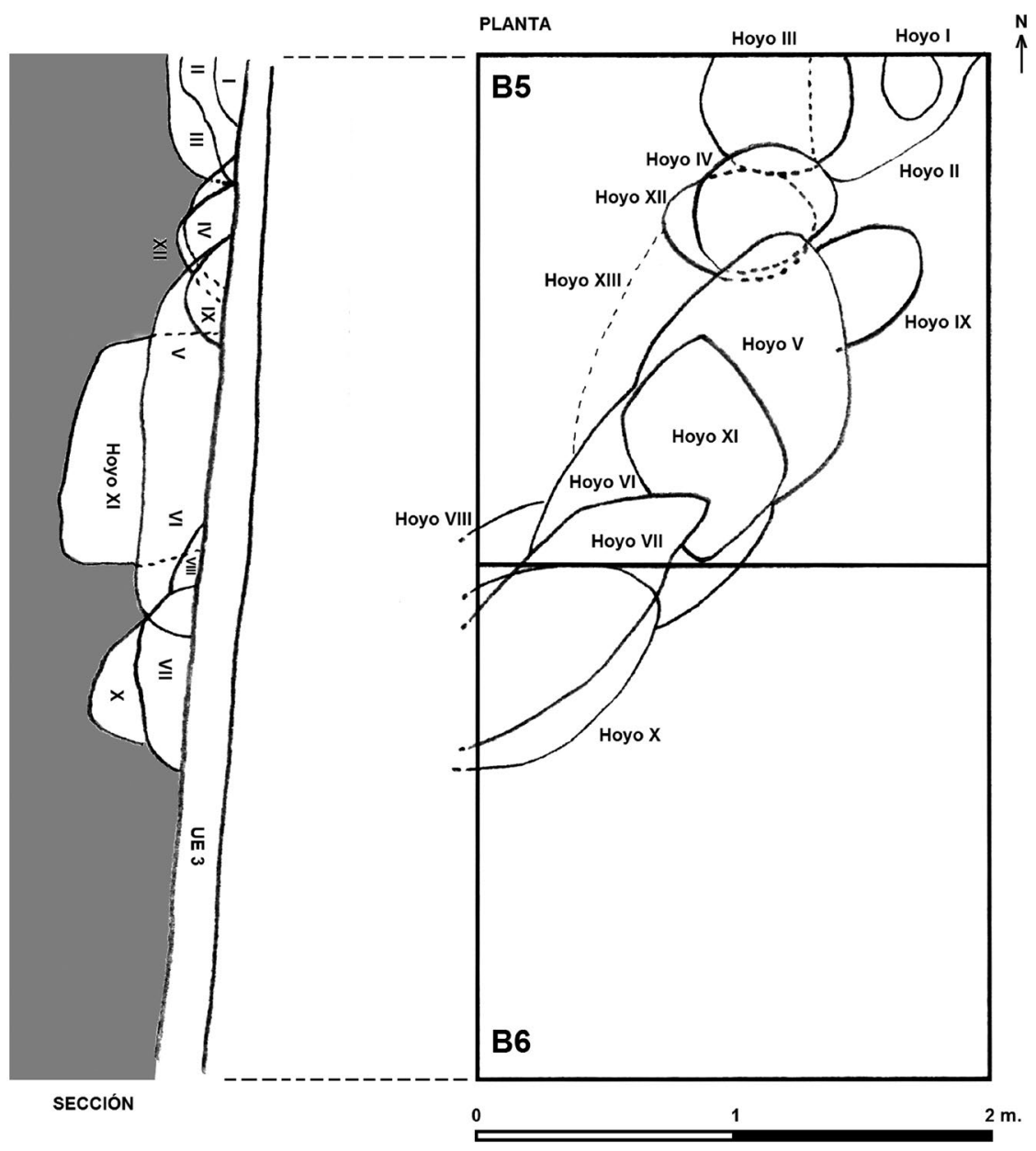

Figura 9: Bernorio, Área 7, Necrópolis. Plano con planta y perfil del transect realizado en la campaña del 2008 con los hoyos excavados (Infografía de Equipo Bernorio y S. Domínguez Solera y D. Vacas Madrid IMBEAC).

(en torno al 100 a. C) y sitúan su origen en el noreste de la Península Ibérica, extendiéndose desde allí a otros territorios del Imperio Romano (Demetz, 1999 en Buora, 2005: 85). Es de destacar que todo indica que el resorte de la fíbula que es «de tubo» y ha perdido los remates laterales de dicho resorte y la mortaja, de ahí que el extremo esté algo desfigurado. También hay que tener en cuenta que esta fíbula está un poco modificada, por eso la aguja sobrepasa con creces el largo del arco. A este respecto también señalar que la decoración parece una aportación o modificación con elementos propios de los estilos decorativos indígenas (Fig. 8B).

El análisis de las estructuras y materiales recuperados en la campaña de 2007 nos permitió establecer que la superposición y abigarramiento de los hoyos estaría indicando un uso deliberado, reiterado e intenso de un mismo espacio. Esto refuerza la interpretación de que, pese a que no se haya conservado una estructura delimitadora, los hoyos habrían estado reunidos en un espacio concreto luego cubierto por un túmulo de tierra que los selló. En un primer momento no fue posible establecer una cronología exacta por tipología de los materiales de los hoyos y, por extensión, de este espacio de necrópolis; solamente pudimos establecer que se trataba de materiales de finales de la Segunda Edad del Hierro.

\section{CAMPAÑA DE 2008}

La campaña del 2008 fue diseñada y ejecutada como una continuación de la anterior. En esta segunda intervención se pretendía obtener más información sobre esta área, ya que, tras la intervención de 2007, resultaba imposible demostrar inequívocamente que los hoyos excavados fueran tumbas humanas. Y es que, aunque todo indicaba que se trataba de restos de rituales funerarios, ya que se recuperaron cenizas, carbones, elementos de ajuar metálico con indicios de haber sido quemados y restos óseos de fauna con evidencias de haber sido cocinada y consumida, no se habían podido identificar inequívocamente restos óseos humanos. Por tanto, cabía la posibilidad de cuestionar si realmente se trataba de un espacio de necrópolis.

Por tanto, se decidió realizar una ampliación del transect excavado en 2007, ampliando en 2 cuadros más la Cata 1. Estos nuevos cuadros (B4 y B5) se 

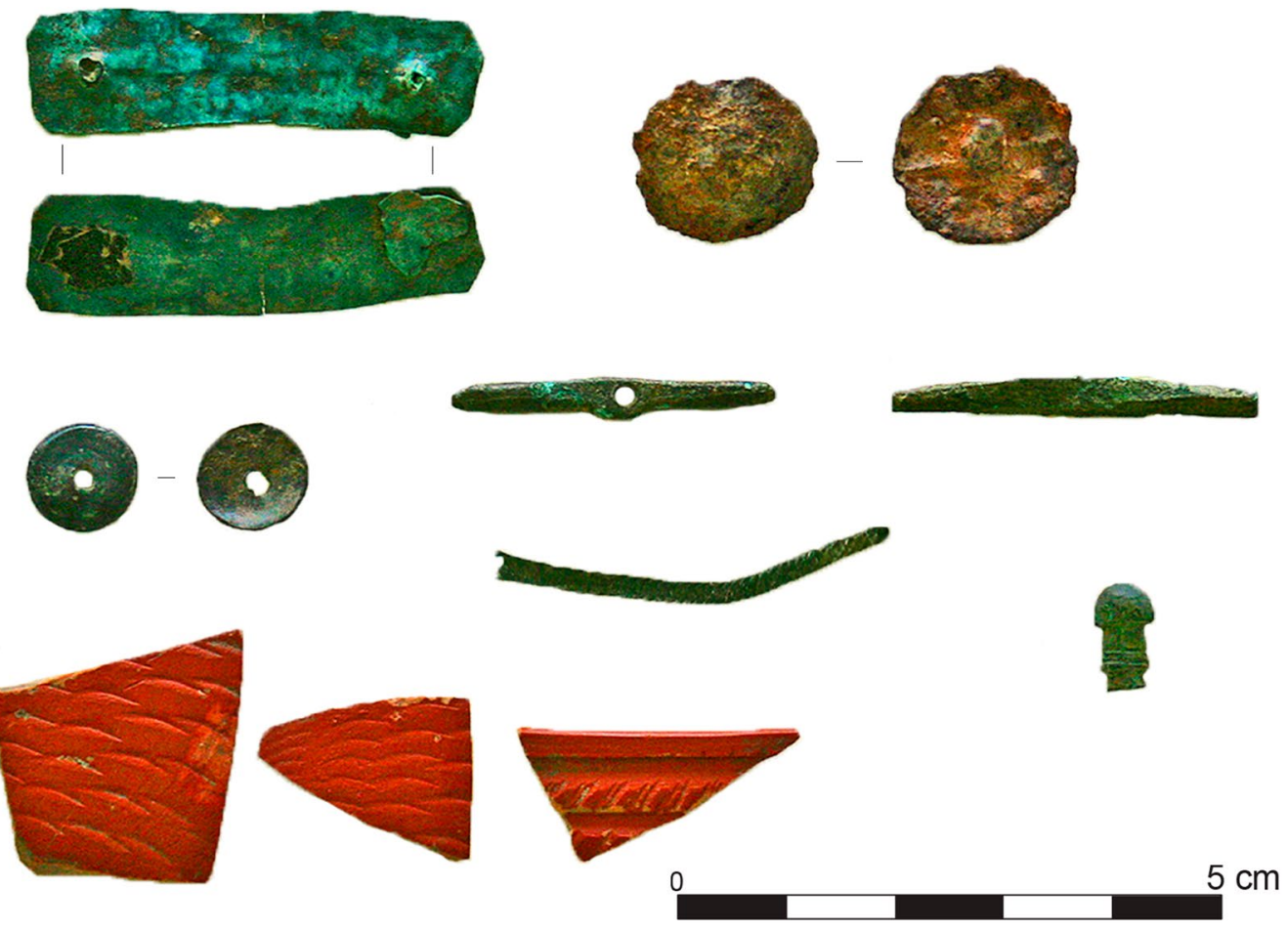

Figura 10: Bernorio, Área 7, Necrópolis, Campaña 2008. Conjunto de parte del ajuar Hoyo X con algunos de los materiales metálicos y fragmentos de cerámica de tipo sigillata (Fotografías Equipo Bernorio, Infografía de D. Vacas-Madrid IMBEAC).

plantearon hacia el este de los abiertos el año anterior, en parte para hacerlos coincidir con un hoyo que había quedado sin excavar en el perfil. En esta ampliación se identificaron y excavaron 13 hoyos. En esta segunda campaña cada hoyo se nombró con números romanos para evitar cualquier error con los excavados en el 2007.

Los trece hoyos aparecieron agrupados y relacionados entre sí formando un sistema. La superposición observada entre los hoyos permitió establecer cuáles eran más modernos y cuáles más antiguos (Fig. 9). La única excepción fue la de los Hoyos V y VI, cuyo contenido era idéntico y no se pudo saber cuál se superponía a cuál. Entre ambos, para separar los materiales extraídos de su interior, se optó por establecer una línea arbitraria. No obstante, es posible que realmente se trate de un mismo hoyo con una planta un tanto equivoca en forma de «ocho». La superposición de los hoyos (ya detectada en las estructuras excavadas en el año anterior) significa que se excavaban unos encima de otros de forma relativamente consciente, y que era más importante la reutilización constante del mismo espacio que alterar los hoyos más antiguos. Esto evidentemente tiene un significado ritual y simbólico que debe ser tenido en cuenta.

En el proceso de excavación todos los hoyos fueron excavados y documentados sucesivamente, procesándose y cribándose las tierras extraídas hasta vaciarlos completamente. Además, se tomó una muestra de tierra y otra de hueso no identificable para la datación radiocarbónica de cada hoyo. Las muestras de tierra se tomaron con el objetivo de realizar en el futuro una analítica especializada que pudiera aportar más datos sobre lo encontrado en esta área.

En todos los hoyos excavados en la ampliación del 2008 de la Cata 1, salvo en el $N^{\circ}$ XIII, se identificaron restos óseos de fauna. En la extracción y a simple vista se identificaron restos de ciervos (Cervus elaphus), jabalíes (Sus scrofa) y corzos (Capreolus capreolus). También se identificaron pequeños fragmentos de huesos cremados y quemados. Los materiales de ajuar, muy fragmentados, consistían en restos de cerámica modelada y torneada, destacando algunos fragmentos de terra sigillata de pequeños recipientes tipo cuenco recuperados en los Hoyos XI y X.

También se recuperaron algunos fragmentos de objetos metálicos muy fragmentados y pequeños. Como habíamos documentado en la Campaña de 2007, los ajuares metálicos de cada hoyo eran en realidad sólo fragmentos parciales de objetos (pars pro toto) y mostraban signos claros de haber sido previamente destruidos durante el ritual.

En algunos hoyos los restos de objetos metálicos fueron muy escasos. Así, en el Hoyo IX se recuperó un solo fragmento de hierro. En el Hoyo XI y el Hoyo XII un solo fragmento de bronce. En otros casos se pudieron recuperar una mayor cantidad de fragmentos. En el Hoyo $\mathrm{V}$ se identificaron fragmentos de un cuchillo de hierro con mango de cuerna y quemado, 2 fragmentos de hierro y 1 fragmento de un objeto de bronce indeterminado. En el Hoyo VI se recuperó un fragmento de cadena de hierro, una aguja de fíbula, un remate de 
hierro, chapas de hierro remachadas, 2 fragmentos de hierro y uno de bronce de un objeto indeterminado. En el Hoyo X, el de mayor contenido en fragmentos metálicos, se recuperó un remate y un eje de fíbula, una plaquita, una aguja, una aguja de colgante, una aguja de cinturón, una cuenta, una placa, un anillo, una barrita, un adorno de cinturón, un fragmento de chapa con dos remaches y 14 pequeños fragmentos; todo ello realizado en bronce. Además, en hierro, un fragmento de varilla (podría tratarse de un fragmento de punta de flecha), fragmentos de barritas y de una chapa, así como una tachuela de caliga (Fig. 10).

En el estudio de materiales hoyo por hoyo de las dos campañas (2007 y 2008) que realizamos al finalizar la segunda, se apreciaba ya cómo los hoyos tenían fragmentos de hueso cocinado/alterado por calor, de hueso quemado, de hueso cremado, fragmentos de objetos metálicos y de recipientes cerámicos, en apariencia, la mayor parte de pequeño tamaño. No todos los hoyos contenían todos los tipos de restos, pero todos los indicios apuntaban, en cualquier caso, a que estábamos ante un tipo de ritual funerario en el que se recogía «una parte por el todo» (pars pro toto) de los elementos que evidentemente debieron de tener algún papel destacado en dicho ritual de cremación y en el banquete funerario.

\section{PROSPECCIONES GEOFÍSICAS EN EL ÁREA 7}

También, en la campaña de 2007 un equipo de investigadores pertenecientes entonces a la Universidad de Frankfurt am Main (en la actualidad vinculados a la Universidad de Marburgo), dirigidos por el Prof. Dr. Felix Teichner, realizó una campaña de prospecciones geofísicas del subsuelo de la terraza donde se sitúa este espacio de necrópolis. El trabajo consistió en un estudio de magnetometría con el fin de determinar las características del subsuelo y localizar evidencias de posibles estructuras arqueológicas subyacentes. En sus resultados se identificaban una serie de posibles estructuras en zonas próximas a la cata abierta en 2007 (Torres et al., 2016a: 372-374 y Fig. 6).

Los materiales que habíamos obtenido en la campaña anterior pertenecían todos a finales de la Segunda Edad del Hierro mientras que las tumbas excavadas y descritas por San Valero contenían restos más antiguos, de inicios de la Segunda Edad del Hierro (San Valero, 1944: 28-33; 1959: 8-9). Las estructuras documentadas por este investigador presentaban, en principio y a partir de los datos generados, una morfología diferente a la de los hoyos que nosotros habíamos excavado. Cabía la posibilidad de que la imagen del radar nos estuviera mostrando una zona de necrópolis similar a la que encontró San Valero. Con estos objetivos iniciamos los trabajos del 2008 en el Área 7.

Tomando como referencia los cuadros abiertos en 2007 fue planteada una trinchera (denominada Cata 2) cuya trayectoria discurría a $60 \mathrm{~m}$. en paralelo al transect realizado en el año anterior, aproximadamente en la zona media del área prospectada por el equipo de la Universidad de Frankfurt am Main. Se abrieron dos cuadros de $2 \times 2 \mathrm{~m}$ que dieron resultados negativos con tan solo algunos hallazgos poco significativos en el nivel de arada, más superficial. Bajo este nivel alterado por las labores agrícolas no se identificaron más que arcillas estériles de coloración rojiza y amarillenta. En uno de los cuadros se excavó hasta unos $70 \mathrm{~cm}$ de profundidad, llegando al nivel geológico de base, sin resultados. En estos dos sondeos no localizamos estructura alguna, pero fue debido al azar, ya que en campañas posteriores sí se han localizado estructuras en esta misma área.

\section{ESTUDIO ZOOARQUEOLÓGICO (TAFONÓMI- CO Y TAXONÓMICO) DE LOS RESTOS ÓSEOS DE FAUNA}

El estudio taxonómico y tafonómico de los restos óseos de fauna recuperados en el Área 7 se realizó a partir de un peso total de $7260 \mathrm{~g}$ de material óseo y teniendo en cuenta las directrices de varios manuales genéricos (Schmid, 1972; Nickel et al., 1977; Sisson y Grossman, 1982; Mariezkurrena y Altuna, 1983; Prummel y Frisch, 1986; Barone, 1990; Vázquez et al., 1995; Halstead y Collis, 2002; Quesada, 2004; Mariezkurrena, 2004; Varela y Rodríguez, 2004; Hillson, 2005; Alcántara et al., 2006; Yravedra, 2006). Estos restos habían sido recuperados tanto en el área excavada como en su entorno inmediato, y provenían de las campañas de 2004 (prospección), 2006 (prospección), 2007 (excavación) y 2008 (excavación). Sin embargo, no todos ellos resultaron útiles para el desarrollo de una estadística: sólo se utilizaron los recuperados en los contextos estratigráficos de los hoyos y que no procedían de los estratos superficiales y los de niveles revueltos por la acción de la arada. En las campañas de 2004 y 2006 se prospectó la zona luego intervenida exclusivamente, por lo que los $949 \mathrm{~g}$ de hueso obtenidos en ambas $(749+200 \mathrm{~g})$ proceden de superficie en el entorno del túmulo de tierra luego excavado. En la campaña 2007 se obtuvieron 3211 g, de los cuales estaban en estratigrafía útil $2102 \mathrm{~g}$. En la campaña de 2008 se recuperaron $3100 \mathrm{~g}$, de los cuales sólo $2759 \mathrm{~g}$ estaban en el interior de los hoyos. Estos restos útiles de las campañas 2007 y 2008 del interior de los hoyos y que suman $4861 \mathrm{~g}$ (el 66\% del total) son los que se han estudiado detalladamente y los que sirven para el desarrollo de una estadística y para su estudio e interpretación.

Los restos recuperados en superficie y en niveles alterados por el arado se han analizado y revisado con el fin de identificar las especies, marcas y otros datos útiles y destacables, pero no se han cuantificado. En este sentido, es ilustrativo el caso de los materiales procedentes del nivel alterado por el arado de esta área si lo comparamos con el registro del interior de los 


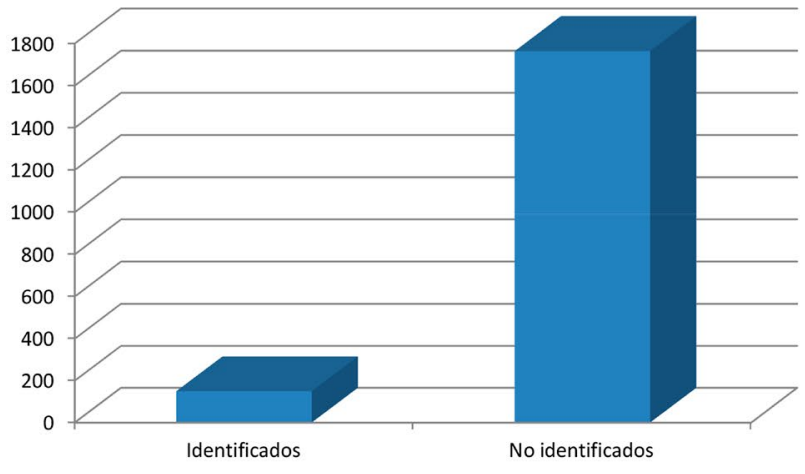

Figura 11: Estudio zooarqueológico. Representación gráfica de la cuantificación de restos por especies. Hemos distinguido primero los restos NI de los que sí han podido atribuirse a alguna especie (Infografía de S. Domínguez Solera, Equipo Bernorio IMBEAC).

hoyos: los materiales procedentes del nivel de arada tienen unas características idénticas al material óseo de fauna procedente de las zonas habitadas que se ha analizado. Ello significa que una parte significativa de éstos procede de las zonas de habitación, llegando al Área 7 por la erosión de la cima del cerro. Otra parte, en apariencia más pequeña, parece proceder muy posiblemente de hoyos alterados o destruidos por la acción de la maquinaria agrícola.

Aunque se podrían haber presentado estadísticas individualizadas (hoyo por hoyo), decidimos, como objetivo final, obtener porcentajes y valores generales de conjunto, dado que consideramos todas las estructuras excavadas como parte de un conjunto (sistema), pero los resultados hoyo por hoyo están también registrados.

\section{ESTUDIO TAXONÓMICO}

Los restos óseos de cada hoyo presentan conjuntos con una gran fragmentación. Hemos recogido y cuantificado las lascas y fragmentos incluso inferiores al centímetro, puesto que significan más del $90 \%$ del total. Esto explica la ingente cantidad de elementos «No Identificados» (NI) que se aprecian en la correspondiente tabla. Además, se ha realizado también otra tabla resumen con el «Número Mínimo de Individuos» (NMI). Esta fragmentación nos ha imposibilitado hacer una estimación de elementos presentes porque no creemos que ésta pueda hacerse de forma fiable. Debemos, por tanto, asumir las limitaciones que significan el sesgo y la elevada fragmentación de los restos, junto a la consabida gran alteración de las superficies óseas por raíces y otros agentes biológicos distintos a la acción de animales y ser humano. También la disposición de los hoyos, invadiendo unos la estructura de otros y, probablemente, alterados en algunos casos por remociones contemporáneas debidas al cultivo, obliga a tener precaución. Debemos asumir que es posible que al menos una parte del contenido de los hoyos puede haberse mezclado en mayor o menor

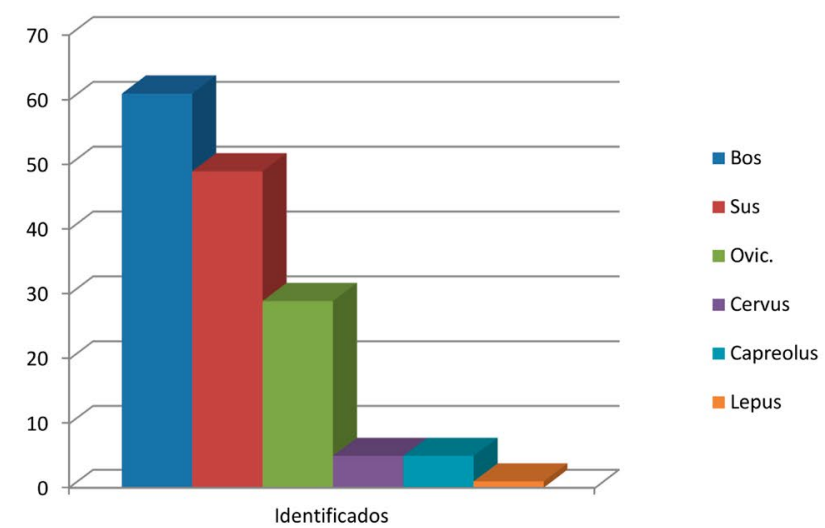

medida. Pero, aun teniendo en cuenta todo esto, se han obtenido unos resultados que evaluamos como bastante útiles para la interpretación de los distintos fenómenos y procesos en los que los restos óseos se vieron envueltos.

Se han analizado, resto por resto, un total de 2014 fragmentos. De este total de restos analizados, 1764 no han podido ser atribuidos a especie concreta y 150 sí. Sólo 321 de ellos no han podido identificarse. 1041 son elementos apendiculares, 461 axiales y 181 craneales. Son siempre las diáfisis, en concreto las lascas de ellas, las más abundantes de todos los restos. Ningún animal ha aparecido representado completo en el interior de los hoyos. Aquellos restos con fractura reciente, producto de la división por rotura durante la excavación o la limpieza, se han tenido en cuenta para la obtención de una cifra de fragmentos corregida. Ello significa que los porcentajes se realizan empleando la totalidad del contenido presente en los hoyos en el momento de su excavación. El número mínimo de individuos será por este motivo, y unido a la enorme fragmentación de restos (lascas NI), menos certero con respecto a la realidad (Fig. 11).

En el interior de los hoyos se han documentado sólo 6 especies animales: bovinos (Bos taurus), suidos (Sus domesticus/scrofa) $)^{5}$, ovicápridos (Ovis/ Capra $)^{6}$, ciervos (Cervus elaphus), corzos (Capreolus capreolus) y lagomorfos (Oryctolagus cuniculus/ Lepus europaeus $)^{7}$. Principalmente se han recuperado fragmentos de bóvidos (Bos taurus) siendo menos

5. Debemos recordar la dificultad de diferenciar cerdos u otros animales domésticos de sus parientes salvajes en este contexto cronocultural.

6. En este caso la misma advertencia que en el caso anterior ( Vid cita $\mathrm{N}^{\circ} 5$ ). Pero debemos, además señalar la fragmentación de los restos y el hecho de que no se recuperen suficientes retos con elementos diagnósticos suficientes imposibilita una distinción fiable entre oveja y cabra.

7. Es probable que la presencia de los restos de este tipo de especies sea debida a intrusiones por los hábitos de estos animales, pero no necesariamente. 
numerosos los de suido (Sus domesticus/scrofa) y ovicáprido (Ovis/Capra). Al margen de los jabalíes ( Sus scrofa) que pueda haber contenidos en la cifra de suidos, las especies salvajes presentes en este sector de la necrópolis son inferiores numéricamente. La estimación del NMI subraya, a grandes rasgos, estas valoraciones. No obstante, según el NMI el número de bóvidos es inferior al de suidos y al de ovicápridos aunque sigan estando estas tres especies, por la estadística del número de restos, notablemente más representados que los cérvidos.

Según se puede apreciar en la Tabla General (Fig. 12), los restos identificados de animales pequeños pese a haberse recogido hasta las más ínfimas astillas de hueso- sólo son 18, el número de animales medianos (ovicáprido, suido y cérvidos) es de 233 y el de animales grandes de 161. Al no haber documentado presencia de caballo (Equus caballus) en el interior de los hoyos, los bóvidos (Bos Taurus) es el único animal cuyos restos han de entenderse como de animal grande. Sin embargo, sí ha aparecido caballo en el estrato de revuelto superficial, pero no podemos incluirlo como especie procedente del interior de los hoyos, dado que puede provenir de la precipitación de restos desde las áreas de habitación de la parte superior de la montaña.

De los 183 restos a los que se les ha podido atribuir una estimación de edad, 13 (que representan el 7,1\%) pertenecen a animales claramente infantiles, 32 (el $17,5 \%$ ) a juveniles en proceso de desarrollo y 138 (el $75,4 \%$ ) a animales adultos. Indiscutiblemente, pese a la cifra enorme de fragmentos no atribuidos a ninguna franja de edad (NI), el dato es representativo de una superioridad numérica de especímenes adultos. No hay animales salvajes infantiles en principio (queda el interrogante sobre los suidos). Todo esto es indicativamente útil para entender la estrategia de sacrificio de las reses en estos contextos rituales y también en la gestión cinegética para el mismo tipo de contextos.

\section{ESTUDIO TAFONÓMICO Y DE LAS MARCAS SOBRE LOS HUESOS}

En el estudio de las marcas existentes en los huesos no hemos tabulado las que pueden haber sido producidas por raíces, dado que han sido identificadas en casi la inmensa totalidad de los restos (98-99\%). La intensísima alteración por raíces y otras alteraciones bioquímicas dificultan la identificación de otras marcas. No obstante, debemos precisar que las raíces han alterado levemente menos los restos de la necrópolis que los de, por ejemplo, el área de habitación dentro del núcleo.

Las alteraciones antrópicas más comunes son las de fuego. Según la coloración visible de las superficies óseas, producida por la exposición al fuego, las temperaturas de la mayoría de los restos quemados quedan entre los $100 \mathrm{y} \operatorname{los} 300^{\circ} \mathrm{C}$. Algunos fragmentos

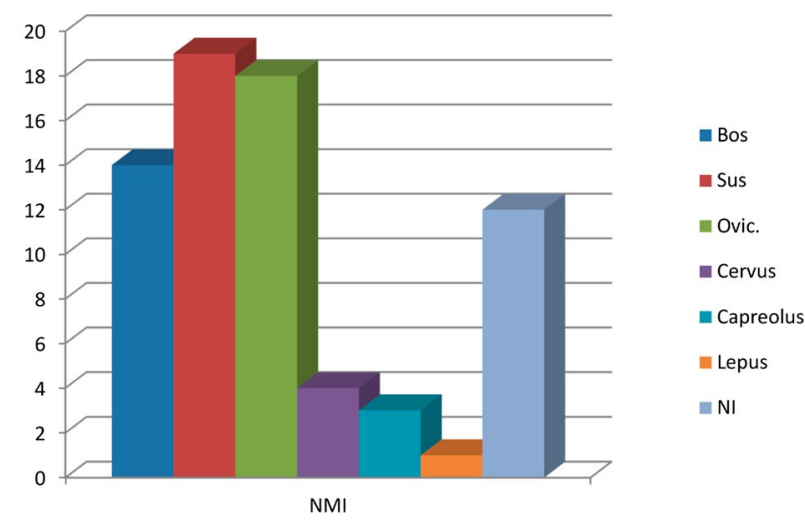

Figura 12: Estudio zooarqueológico. Tabla General con Número Mínimo de Individuos, especie a especie, sobre un total de 71 restos (Infografía de S. Domínguez Solera, Equipo Bernorio IMBEAC).

(siempre inferiores al centímetro) muestran tonalidades grises y blanquecinas (por encima de $\operatorname{los} 300^{\circ} \mathrm{C}$ ) estimamos que corresponderían a las cremaciones de cadáveres humanos. El resto de los fragmentos pertenecen a animales cocinados y/o tan solo quemados.

En lo que se refiere a las marcas de corte identificadas en los huesos animales son las siguientes en representación. En primer lugar, destacar la existencia de sección de vértebras y costillas y la sección total de fragmentos de epífisis y diáfisis. Esto indica una acción deliberada de descuartizado. Pero, dentro de la cadena operativa (sensu stricto Leroi-Gourham, 1971) que podemos reconstruir sobre el tratamiento de la fauna, han de ser anteriores las huellas de desarticulado que están constatadas en las extremidades. Resulta llamativa y curiosa la presencia de huellas de corte en las articulaciones de las pezuñas, lo que indica su desarticulado, práctica poco frecuente.

El descarnado de los lomos y de la carne del cue1 lo -previa decapitación- se demuestra y explica por las huellas de corte presentes en las apófisis espinosas, las costillas y el atlas. El descarnado de las mazas de carne de los huesos superiores de las extremidades es el que indican los cortes leves en las diáfisis y epífisis. Se aprecia la actividad de descuartizado en caderas, costillas y vértebras, lo que puede entenderse como cubicado de carne en porciones destinadas, por ejemplo, a guisos.

También son abundantes las marcas de pisoteo. Mucho más que las de diente. Sobre la interpretación de las marcas de diente (también de incisivo) hay varias opciones posibles, pero ante todo indicar que son notablemente muchísimo menos numerosas, intensas e importantes que las observadas en el área de habitación en el interior del poblado. En la zona de hábitat, además de los perros (Canis familiaris), también pudieron mordisquear y ramonear los huesos cerdos (Sus domesticus) (Greenfield, 1988; Domínguez-Rodrigo y Domínguez-Solera, 2009). Ello indica para los restos óseos de la necrópolis una mucho menor intervención de agentes carnívoros presentes en el momento de la 
formación del contexto que rellenó los hoyos. Pero esa actividad existió y está constatada en los restos.

También hemos documentado, aunque no haya sido analizada sistemáticamente, información sobre los paños de fractura de los restos óseos. Éstos presentan ángulos que difieren de $\operatorname{los} 90^{\circ}$, lo que indica fractura por percusión dinámica (golpes con un filo cortante) y no por presión estática (mordida) (Alcántara et al., 2006). Esto debe ser tenido en cuenta, aunque las marcas de percusión son escasísimas y estén catalogadas en el capítulo de «otros», invisibilizadas en muchos casos tal vez por su confusión con las engorrosas marcas de raíces.

Es necesario dejar constancia de la presencia de tonalidades verdosas tiñendo restos óseos. Este fenómeno se produce como producto de la oxidación de los objetos de base cobre y de los bronces en contacto con los huesos. Se trata de los fragmentos y restos de los metales presentes en los hoyos o tal vez de una transferencia de óxidos producida durante la cremación.

\section{RESULTADOS DE LOS ANÁLISIS DE MUES- TRAS DE TIERRA Y DE LOS FRAGMENTOS DE HUESO RECUPERADOS.}

De los materiales recogidos en el interior de los hoyos se entregaron para su análisis diez muestras de fragmentos de tierra y esquirlas de hueso cremado y quemado al Laboratorio de Arqueología Forense de la Universidad Autónoma de Madrid (LafUAM), integrado en el Instituto de Ciencias Forenses de la UAM (ICFS) y dirigido por el Prof. Dr. Ángel Fuentes. La finalidad era realizar un análisis tanto de las tierras como de los huesos a través de microscopía. El análisis de los restos óseos se realizó en dos vertientes: el tratamiento que los huesos habían sufrido y la identificación de la especie a la que pertenecían éstos. De este modo se podría verificar si se trataba de rituales realizados con cadáveres humanos y si estos incluían también animales. El análisis de las tierras podía aportar información complementaria sobre el tipo de procesamiento que habían sufrido los huesos.

De las diez muestras recibidas se pudo comprobar que tres no contenían más que cenizas y tierra. Las restantes muestras resultaron muy interesantes porque, aunque no contenían una gran cantidad ni de huesos ni de cenizas, sí se pudo constatar que contenían pruebas de que inequívocamente habían pertenecido a cremaciones ex profeso de mamíferos de gran tamaño. Por este motivo resultaba extraño la pequeña cantidad de huesos cremados que contenían las muestras y el pequeño tamaño de los fragmentos de hueso, lo que hacía más complicado su análisis.

\section{ANÁLISIS DE TIERRAS Y MICROCARBONES}

El análisis de las cenizas con microcarbones que acompañan a las muestras de tierra y huesos cremados resulta interesante por el número y variedad de los carbones. Pero en general de trata de carbones de origen vegetal, procedentes de ramajes de calibre mediano de tipo arbustáceas fibrosas, o bien de plantas de más porte, del tipo leñosas. Al menos en un caso detectamos indicios de restos carbonizados de lo que parecía podía haber sido un tejido vegetal, por el aspecto fibroso de los residuos. Además, se sometieron a flotación los restos de tierra sin que se apreciaran otros restos significativos. Hasta el momento no ha resultado posible realizar análisis de estas muestras para identificar la especie vegetal a la que pertenecen estos fragmentos de carbones.

\section{ANÁLISIS DE RESTOS ÓSEOS}

Dado lo fragmentado y pequeño de la muestra ósea en un primer análisis se plantearon ya serias dudas de que la gran parte de la muestra pudiera ser calificada como indudablemente humana. Hubo una sola excepción, la de un fragmento que con mucha probabilidad podía ser un hueso columnar humano, tal vez de una tibia. En dos de las muestras se identificaron indudablemente huesos animales. En uno de estos casos los restos óseos animales iban acompañados de otros restos que podrían ser humanos. En otro caso se identificó un fragmento de cráneo, de tabla ósea interna, que desgraciadamente era demasiado pequeño y topográficamente no se podía vincular a un cráneo humano. Por tanto, no se podía descartar que pudiera tratarse de un fragmento óseo de un mamífero de mediano porte como un ovicáprido (Ovis/Capra) o un perro (Canis), pero se descartó su pertenencia a un micromamífero o a animales de gran talla del tipo equino (Equus) o bovino (Bos).

En el análisis microscópico ningún fragmento de hueso mostró restos de adherencias de tejido o de manchas de sangre que fueran compatibles con cualquier estudio de grupo sanguíneo o de cromosomas, análisis que también podrían haber sido ser indicativos y aportar una gran cantidad de información, incluida la determinación del sexo. El motivo de esto es que la totalidad de los huesos aportados en las muestras habían sido cremados a altas temperaturas $\mathrm{y}$, en algunos casos, por tiempo prolongado, lo que había volatizado este tipo de residuos. No obstante, se preservaron en los restos algunas cuestiones de mucho interés.

En todos los casos se constata que se trata de cremaciones voluntarias, no casuales o secundarias a ningún otro tratamiento de los restos (humanos o animales). El tratamiento sufrido por los huesos pone de manifiesto que se ha producido con la finalidad exclusiva o principal de reducir a cenizas ese cadáver. El análisis microscópico demuestra que las adherencias al hueso son primero cenizas y luego tierra. También se constata que los cadáveres mantuvieron tejido blando, quizás muscular, 
adiposo, etc., adherido al hueso durante el proceso de cremación. Se observa claramente una fina capa blanquecina en la cara externa del hueso, resultado de haberse quemado residualmente ese tejido sobre el periostio por un tiempo superior al de la combustión, creando este requemado residual más intenso. Por lo tanto, en todas las ocasiones la finalidad última de la cremación fue la de reducir a ceniza un cadáver, hasta hueso, sin tratamiento ni descarnación previa (no han aparecido huellas observables previas ni a posteriori).

En un caso, al menos, se identifica también un animal de gran talla, pues los restos de hueso, si bien muy fragmentarios, conservan una coloración oscilante que indica que se sometieron a temperaturas diferentes. En el caso de un mismo animal o cuerpo, sería sintomático de su gran talla. Por lo general, se puede concluir que la temperatura fue intensa, homogénea, pero limitada en el tiempo. Hay pocos casos de destrucción tisular por deshidratación profunda.

A juzgar por la escasa cantidad de materia conservada, da la impresión de que lo que tenemos es el resto de una cremación intencionada, pero sólo el relicto de esa cremación, una parte que fue deliberadamente retirada y conservada. Para ello, a juzgar por el análisis microscópico, los huesos sugieren que el cadáver cremado (animal o humano) fue reducido a un fardo o molturado, ya que no se consiguió la incineración completa. Todos los huesos muestran una forma rectangular, cuadrangular, regular, sugerente de haber sido sometido a presiones, tensiones y hasta cortes, inmediatamente tras la cremación; cuando el hueso todavía mantenía un cierto grado de hidratación. En algún caso también hemos documentado que esta fragmentación fue asimétrica, por presión y sin intervenir instrumental alguno, y se ha podido producir por estallido a causa del calor. Tal es el caso del fragmento de cráneo, que parece sugerir un estallido craneal por sobrepresión del contenido endocraneal sometido a altas temperaturas.

En conclusión, lo que tenemos es el residuo mínimo que queda tras haber combustionado varios cuerpos, de talla mediana o mediana grande, entre los que caben restos humanos por supuesto, que han sido quemados, con alteraciones posteriores a la muerte (descarnados, etc.) pero no hasta la incineración; por un periodo de tiempo más bien corto, pero a fuego intenso. Una vez producida la cremación, los restos han sido triturados, por presión física o con la ayuda de instrumental, para lograr el efecto de incineración. Estas cenizas y huesos se han retirado, quedando apenas los pequeños fragmentos que nos han llegado, casi en su mayoría restos de carbones.

\section{ESTUDIO HISTOLÓGICO}

El estudio histológico de la muestra de restos óseos de Monte Bernorio fue realizado también en el laboratorio
LafUAM $^{8}$. Se había descartado previamente la posibilidad de realizar análisis de tipo genético por la desnaturalización del ADN ni de tipo antigénico (ELISA) por el proceso de combustión sufrido por los huesos. La fragmentación de los huesos y su escaso número impedían una identificación macroscópica segura para determinar, de forma indudable, que pertenecieran a humanos. La única manera posible de estar seguro en los casos de atribución dudosa de los restos óseos era realizar un análisis histológico.

Para determinar el origen y procedencia de cada uno de los fragmentos óseos se siguieron los métodos de Hillier y Bell (2007) y Ramalho et al. (2003). Las mediciones son frecuentes en los estudios histológicos con el propósito de distinguir entre humanos y animales.

Se midieron el diámetro de los sistemas de Havers (osteonas) y el diámetro de los canales de Havers, ambos en micrómetros, con una barra de calibraje facilitada por el programa de toma de imágenes. Para obtener los máximos, mínimos, medias y dispersión se realizó un estudio de estadísticos descriptivos, y los datos fueron introducidos en una hoja de cálculo Excel para obtener un gráfico donde los resultados quedaran representados. Finalmente, se contrastaron nuestros resultados con los de Hillier y Bell (2007).

El estudio se complementó realizando un análisis e interpretación de los caracteres histomorfológicos en el que se detalló la forma, tamaño y número de los sistemas de Havers, así como de los diámetros de los canales de Havers. Según Ramalho et al. (2003), cada especie animal presenta unas características histológicas propias que permiten diferenciarlos unos de otros. Con esto, el tejido óseo humano presenta sistemas haversianos de gran diámetro, así como los canales de Havers, con forma elíptica, distribuidos homogéneamente y poco numerosos. Si una muestra histológica no presenta tales características, se descarta inmediatamente la idea de que se trate de hueso humano.

Por su parte dentro de las distintas especies animales también hay diferencias: la cabra presenta en su tejido óseo osteonas con forma irregular, poco numerosos y sin una distribución homogénea. La oveja puede llegar a confundirse con la cabra, salvo que la distribución de las osteonas es homogénea, presenta un diámetro medio ligeramente mayor y son numerosas. El cerdo presenta canales de Havers generalmente pequeño y los sistemas de Havers son numerosos, tienen una morfología circular y una distribución homogénea. Por

8. El estudio de estos restos corrió al cargo de la bióloga A. Rodríguez Trigo bajo la supervisión del Prof. Dr. Angel Fuentes en el laboratorio LafUAM de la Facultad de Filosofía y Letras de la Universidad Autónoma de Madrid entre los años 2013 y el 2014. Los resultados fueron presentados dentro de su trabajo de Fin de Master en Ciencias Forenses y Criminalísticas del Instituto de Ciencias Forenses y de la Seguridad, siendo defendido en Febrero de 2015 en la misma universidad. 


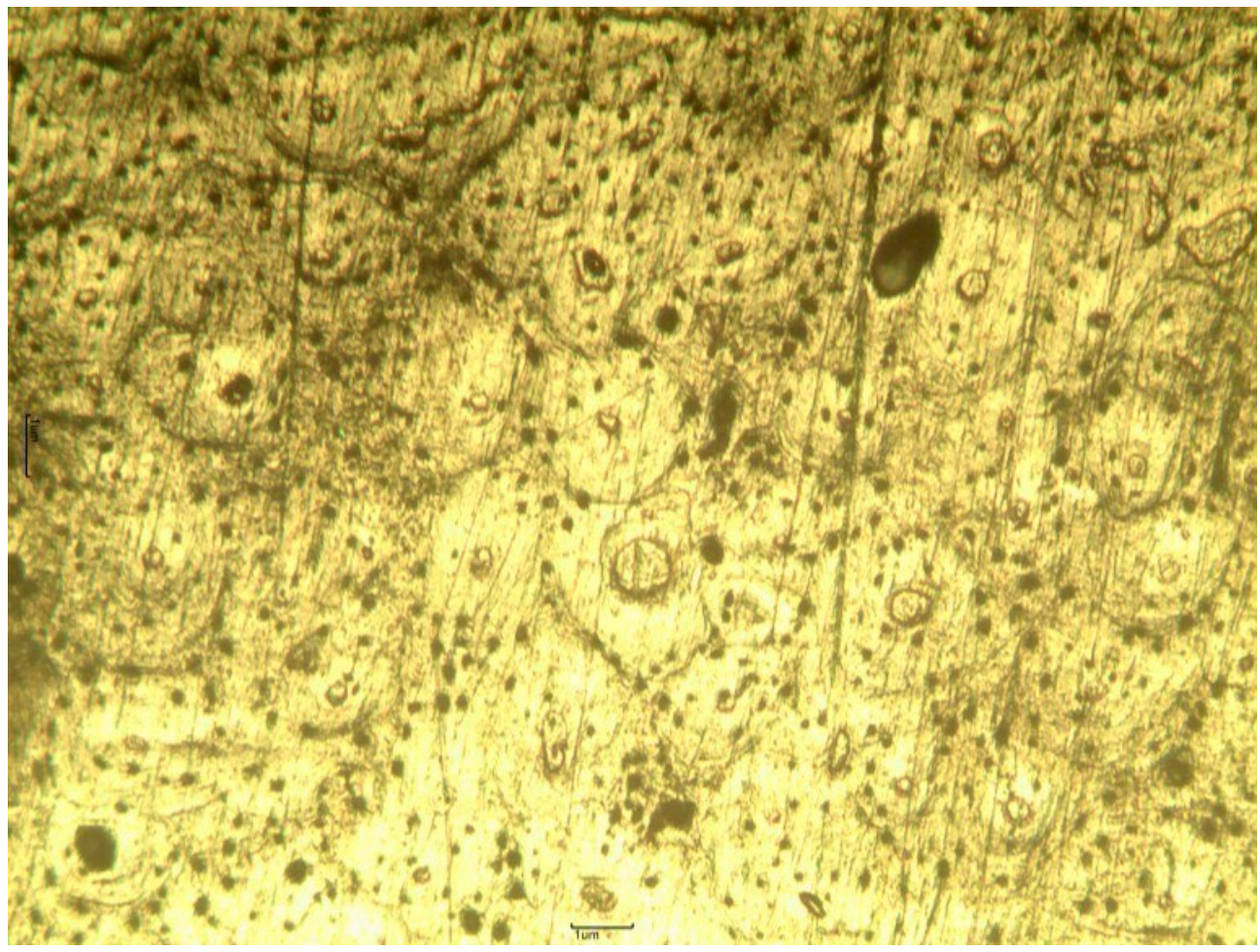

Figura 13: Fotografía de osteona humana (Lamina 5Ax50b) procedente de los restos óseos analizados (Fotografía A. Rodríguez Trigo LafUAM).

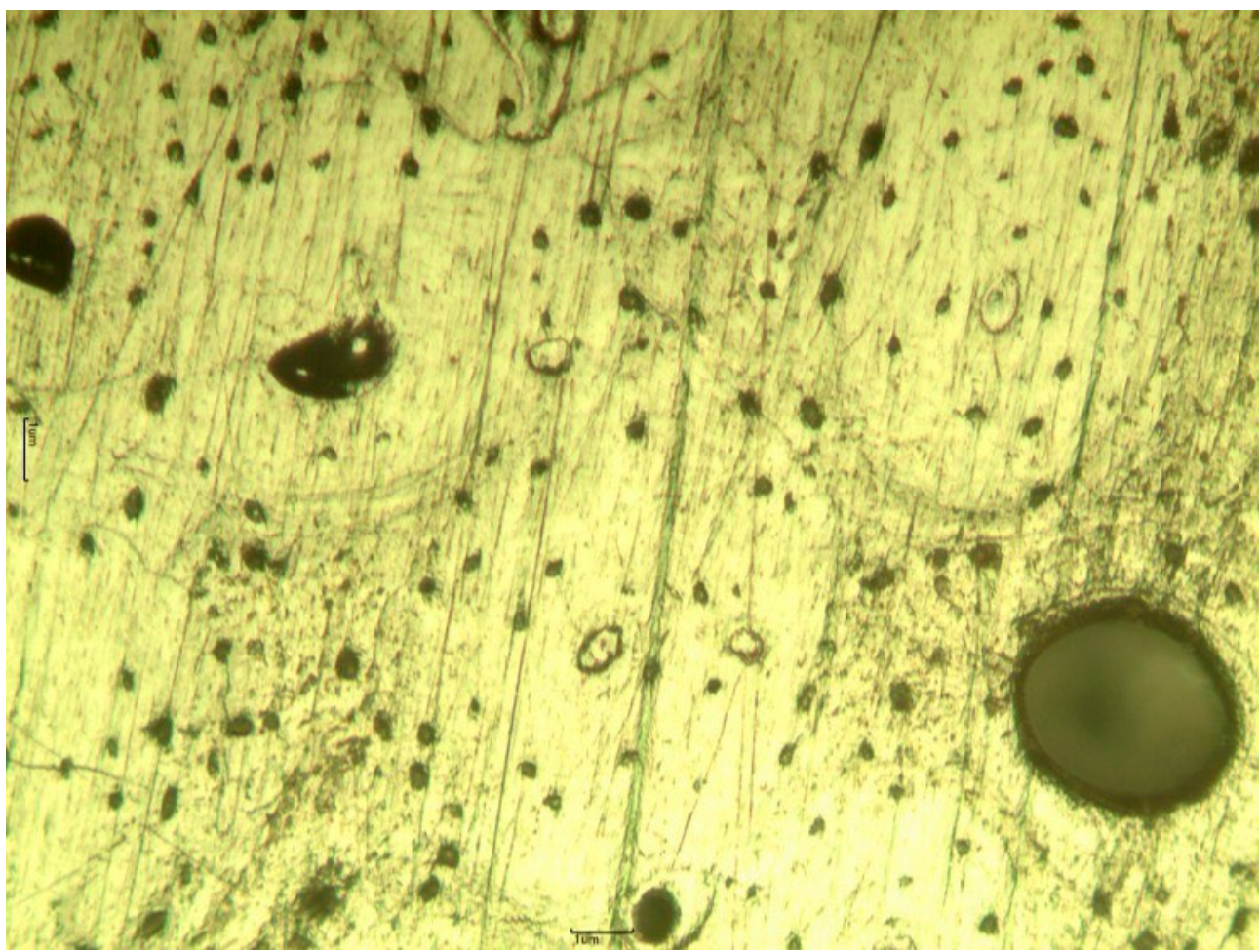

Figura 14: Fotografía de osteona humana (Lamina 5Ax100b) procedente de los restos óseos analizados (Fotografía A. Rodríguez Trigo LafUAM).

último, en la vaca los sistemas de Havers son numerosos, tienen una morfología irregular, con un diámetro pequeño y una distribución homogénea. Dicho método se aplicó de manera independiente para comprobar que si se obtenían los mismos resultados.
Algunos autores (Castrogiovanni et al., 2010) consideran que en un análisis histológico de hueso no sólo basta con evaluar los parámetros histomorfométricos o hacer un análisis de los caracteres histomorfológicos, sino que también hay que contabilizar el número de 
laminillas de las osteonas puesto que cada especie animal presenta un número medio que caracteriza a ese tejido óseo. Sin embargo, en nuestro caso no se aplicó este método debido a que no se pudo contabilizar las laminillas al no diferenciarse con claridad.

El principal problema del estudio histológico fue el hecho de trabajar con material arqueológico cremado y con un tamaño que apenas superaba unos cuantos milímetros. Así mismo, también se tuvo que hacer frente al problema de separar el material óseo del noóseo. Hubo casos en los que se confundieron fragmentos de cerámica con hueso esponjoso a pesar de que las características macroscópicas parecían indicar lo contrario y, en otros casos, se dudaba entre hueso o cerámica, así que se tuvo que hacer la lámina delgada y observar posteriormente al microscopio óptico para despejar dudas. Se analizaron todos los fragmentos óseos a excepción de los procedentes de las unidades 1,7 y 10 , debido a su mala preservación, lo que imposibilitó su identificación.

La evaluación del diámetro de los canales de Havers indicó que el 33\% de los fragmentos eran tejido óseo humano, mientras que el diámetro de las osteonas reveló que el $59 \%$ de los fragmentos eran tejido óseo de cabra.

Por otra parte, el análisis e interpretación de los caracteres histomorfológicos se aplicó de manera paralela a la evaluación de los parámetros histomorfológicos. Los resultados revelaron que el $21 \%$ de los fragmentos óseos eran de origen animal de procedencia caprina, $16 \%$ de oveja y vaca, un $10 \%$ de cerdo. Las piezas dentales representaban el $10 \%$ de todas las muestras analizadas.

La mayoría de los fragmentos que fueron identificados inicialmente como hueso esponjoso por su aspecto macroscópico procedían de la unidad 9 y resultaron ser restos de cerámica incinerada. Se llegó a estas conclusiones después de la observación al microscopio de cristales de cuarzo en dichas láminas.

A la hora de aplicar ambas metodologías se hallaron algunas dificultades. El primer problema fue que no se pudo estudiar la forma, tamaño y número de los canales y osteonas de dos de las muestras, debido a que no se distinguía con claridad el contorno de las mismas (bien por la acción del fuego o por el proceso de pulido de la muestra). De la misma manera, la evaluación de los parámetros histomorfológicos no se pudo realizar en una de las muestras porque no presentaba las condiciones óptimas para su análisis.

El segundo problema fue el asignar una categoría. Teniendo en cuenta los diámetros de los canales de Havers, se comprobó que la mayor parte de las láminas eran de tejido óseo humano seguido del de oveja, no ocurriendo así si teníamos en cuenta las dimensiones de los diámetros de las osteonas donde la proporción era mayor en el tejido óseo de cabra.

Después de terminar con todos los análisis se compararon los resultados con el fin de comprobar si aplicando ambos métodos de manera conjunta llegábamos a las mismas conclusiones. Hubo ciertas muestras en las que los caracteres histomorfológicos indicaban procedencia animal, concretamente cabra, pero, teniendo en cuenta los diámetros de las osteonas indicaba procedencia humana (Figs. 13 y 14).

Otras discrepancias se encontraron en tres láminas que, teniendo en cuenta cada uno de los análisis, indicaban la pertenencia a especies distintas (oveja y cabra). No es de extrañar que esto ocurra, ya que la histología ósea de una cabra y oveja se puede llegar a confundir con facilidad. Incluso recurriendo al diámetro, en ambos casos llegan a solaparse, por lo que es recomendable buscar una mínima diferencia entre ambos.

Llegados a este punto cabe preguntarse, ¿cuál es la mejor metodología en este tipo de estudios? La respuesta es: todas. En un estudio histológico en el que se está tratando de averiguar si un fragmento óseo es de origen animal o humano, no hay que descartar ningún parámetro. Sin embargo, en estudios como el presente trabajo, la aplicación de una metodología u otra va a estar condicionada por el estado de la muestra (su preservación, si ha sido o no sometido a calor y a qué temperatura, etc.)

Es recomendable tener en cuenta la evaluación del diámetro de las osteonas y el análisis de los caracteres histomorfológicos puesto que, como se ha visto, aportan resultados similares. Además, sería recomendable la elaboración de un inventario con hueso arqueológico y/o actual de referencia, tratado y sin tratar con fuego. En este inventario deberían quedar descritas las medidas de los diámetros de los canales de Havers; las osteonas; el número de laminillas de las mismas, su morfología, número y distribución de hueso de las distintas especies animales (incluyendo al ser humano), así como la experiencia del histólogo, que es muy importante para llegar a resultados satisfactorios.

\section{FECHAS DE RADIOCARBONO}

De las muestras tomadas y enviadas para datación por radiocarbono han conseguido ser viables, por el momento, sólo dos muestras. No obstante, pensamos que los resultados son lo suficientemente satisfactorios para datar de modo preciso este sector de la necrópolis.

La primera muestra (Beta-462864) corresponde a hueso quemado extraído del interior del Hoyo 10, excavado en la necrópolis en la Campaña de 2007. Este hoyo es uno de los que ocupaban una posición más superficial, cerrando la secuencia de uso de ese espacio. Además, su contenido estaba protegido por una cubierta de piedras que sellaba sus materiales y hacía muy difícil la introducción a posteriori de elementos distorsionadores por efecto de los trabajos agrícolas desarrollados en esa área. La existencia de un ajuar con elementos de cultura material permitía también una datación aproximada del hoyo a través de éstos. 
La muestra fue enviada para la extracción de colágeno y la datación por radiocarbono al laboratorio Beta Analytics en sus instalaciones de Florida. Pese a la dificultad de obtener materia orgánica válida de un hueso quemado, se procedió, con éxito, a la extracción de colágeno con álcali. El análisis de radiocarbono permitió una datación $2110 \pm 30$ BP. La calibración realizada por el laboratorio a través del software OxCal y la curva de calibración IntCal13 con un $95.4 \%$ de probabilidad a dos sigmas proporcionó un resultado de 204-46 cal BC (Ramsey, 2001; Reimer et al., 2013).

La segunda muestra se trataba de un hueso de mamífero, probablemente vacuno, que había sido cocinado con toda probabilidad en el contexto del banquete ritual de una ceremonia funeraria y que fue enterrado junto con otros restos en el hoyo $\mathrm{X}$, de donde fue recuperado junto con otros objetos y muestras. Fue enviada para la extracción de colágeno y la datación por radiocarbono al Leibniz-Laboratory for Radiometric Dating and Isotope Research (Kiel, Alemania). La cantidad de colágeno extraído representó el 4,5\% del peso total de la muestra ósea. Este valor está muy por encima del valor de referencia mínimo del 1\% (Van Klinken, 1999). Se realizaron tres análisis sucesivos
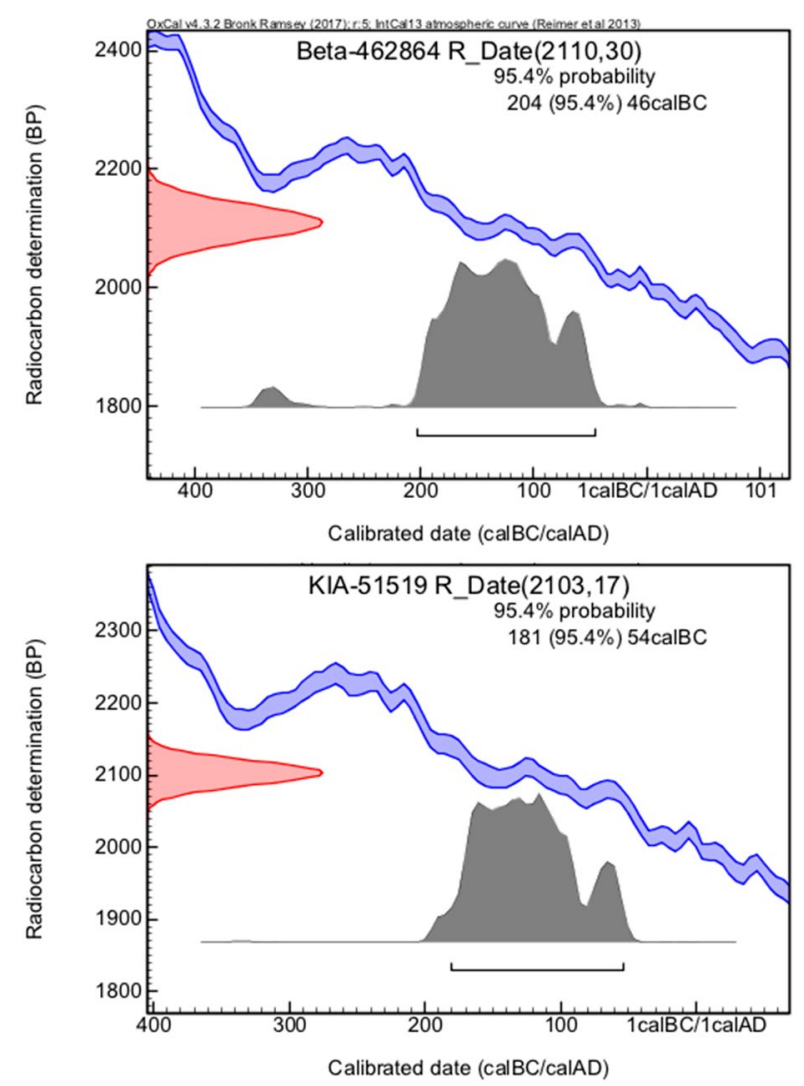

Fig. 15. Comparativa de las tablas que muestran las fechas calibradas obtenidas por análisis de radiacarbono de Beta-462864 y KIA-51519 de la necrópolis del Bernorio (Gráfico OxCal \& R. Fernandes, Department of Archaeology, Max Planck Institute for the Science of Human History and McDonald Institute for Archaeological Research, University of Cambridge). sobre tres muestras bajo una misma referencia de laboratorio (KIA-51519).

Los resultados individuales de cada una $(2054 \pm 34$ BP; $2137 \pm 26$ BP y $2097 \pm 26$ BP) fueron combinados usando la función «R_Combine» del software de OxCal y calibradas en fechas calendáricas usando el mismo software y la curva de calibración IntCal13 (Ramsey, 2001; Reimer et al., 2013). El resultado combinado fue $2103 \pm 17$ BP superando una Prueba $\chi^{2}$ («Chi-squared test») con un nivel significativo de $0,05\left(\mathrm{~T}=3.8\right.$ (para $\mathrm{df}=2$ y $\left.\alpha=0.05 \chi^{2}=6\right)$ ). Esta fecha combinada está en una perfecta concordancia con la fecha (Beta-462864) conseguida en el Laboratorio de Beta Analytics. Sin embargo, dada la alta precisión de la fecha combinada proporciona una fecha calibrada ligeramente más precisa de 181-54 cal a.C. para un rango de probabilidad de 2-sigma (95.4\%). La Figura $\mathrm{N}^{\mathrm{o}} 15$ muestra las fechas calibradas obtenidas por análisis de radiacarbono de Beta-462864 y KIA51519 (Fig. 15).

\section{INTERPRETACIÓN Y DISCUSIÓN}

La excavación de este espacio arqueológico, su documentación y el análisis de los restos recuperados demuestra que se trata de un lugar en el que se desarrollaron depósitos rituales de diversos objetos relacionados con ceremonias religiosas, en concreto, rituales funerarios. Es importante señalar el hecho de que hemos podido documentar el depósito de restos de rituales funerarios, pero que se trata de depósitos de tipo secundario, en un lugar distinto de aquel en que se celebra dicho ritual ya que no se ha podido localizar ningún indicio razonable ni evidencia de que dichos rituales se desarrollaran en este lugar.

Estos rituales, en lo que se refiere a lo documentado a partir de los restos recuperados, consistieron principalmente en la cremación de un cuerpo humano con sus pertenencias más personales como elementos de vestimenta y adorno. El cuerpo era cremado probablemente acompañado de partes de animales como ovicáppridos (Ovis/Capra) y/o cerdos (Sus) y, tal vez, de recipientes cerámicos que contenían productos por el momento completamente desconocidos para nosotros. Para cremar al muerto y sus pertenencias se eligieron principalmente plantas de tipo arbustivas de combustión rápida e intensa. Debido al calor extremo producido en la combustión la carne y la grasa del cuerpo ardieron completamente, interrumpiéndose la combustión al final de ésta, pero antes de la completa deshidratación de los huesos cremados. Una vez apagado el fuego y en caliente, los restos óseos fueron concienzudamente machacados hasta reducirlos, aparentemente, a fragmentos muy pequeños. En este proceso se produjo probablemente la mezcla de los restos óseos cremados del humano y de los fragmentos de animales que acompañaban a este, así como de restos de cerámicas calcinadas. La aparición de fragmentos 
de cerámicas con aspecto de huesos humanos solo distinguibles (y con dificultades) al microscopio es una buena muestra de la intensidad de la acción del fuego en esta ceremonia.

Se han identificado también indicios de lo que hemos denominado como un «banquete funerario», con consumo de animales. Lo indican los huesos de fauna con marcas de procesos de descarnación que han sido calentados y parcialmente quemados (cocinados). Entre las especies presentes en este tipo de ritual de sacrifico y cocinado de animales están presentes especies domésticas y salvajes. Entre las especies domésticas están bovinos (Bos taurus), suidos (Sus domesticus/scrofa) y ovicápridos (Ovis/Capra). Entre las especies salvajes encontramos ciervos (Cervus elaphus), corzos (Capreolus capreolus) y, tal vez, aunque es poco probable, lagomorfos (Oryctolagus cuniculus/Lepus europaeus). En lo que se refiere a los animales salvajes, han sido obtenidos por medio de su caza (cinegéticamente), lo que implica, muy probablemente, una voluntad expresa de su consumo en este tipo de rituales. Todos estos huesos muestran marcas de dientes lo que indica que, tras su consumo, o mientras se producía éste, se arrojaron y fueron mordidos y ramoneados por perros (Canis familiaris), ya que las marcas en los huesos indican la participación de estos animales. Los restos óseos aparecen fragmentados, sin piezas grandes, por lo que no se puede descartar, además de su troceado para preparados de tipo guiso, un troceado o rotura deliberada posterior a su preparado y consumo.

También participaron en el ritual recipientes cerámicos que, a partir de sus fragmentos conservados, serían de reducido tamaño, de tipo cuenco. Estos recipientes los relacionamos con el consumo de bebidas. Tenemos fragmentos de recipientes modelados, torneados del tipo genérico que denominamos como «celtibérico» y de tipo terra sigillata. No se puede descartar que también participaran servicios de madera en estos rituales, no obstante, por el momento no tenemos ninguna evidencia de este tipo de recipientes. En todo caso, los recipientes cerámicos eran también rotos de forma bastante concienzuda en trozos pequeños.

Resulta evidente que se trata de un tipo de ceremonial que posee un orden y unas pautas establecidas, lo que se refleja en la homogeneidad de los restos recuperados en los hoyos. Queda constatado que existe una voluntad de amortizar (destruir ritualmente) todos los objetos y restos de los elementos involucrados en el ritual. Precisamente, a partir de lo recuperado en los hoyos, podemos interpretar que, una vez finalizado este, se procedía a recoger una parte pequeña, e incluso muy pequeña y meramente testimonial, de todos y cada uno de los elementos que han participado en el ceremonial y sus distintos momentos: tierra, cenizas y carbones, esquirlas de huesos cremados, fragmentos de huesos de los animales cocinados para el banquete y fragmentos de cerámica. Es de destacar que la recuperación de fragmentos de huesos ya ramoneados por los perros (Canis familiaris) indica una selección relativamente cuidadosa y concienzuda de los restos. Esto revela un verdadero ritual posterior a la cremación y al banquete en el que se produce una selección de restos de la parte por el todo (pars pro toto). Esta porción reservada es la que se destina a ser depositada en los hoyos.

Se hace evidente que existió un transporte desde la zona de la ceremonia, donde probablemente se celebraron tanto la cremación como el banquete, sin que podamos establecer duraciones o plazos de tiempo. Desde ese lugar se transportaron las partes seleccionadas de los restos hasta el espacio que hemos excavado en el entorno del Bernorio. Es muy posible, dado el reducido volumen de cabida de algunos de los hoyos, que su contenido cupiera en un saco o una caja de madera de un tamaño no muy grande y un peso relativamente bajo. En todo caso, parece innegable que la mayor parte de los restos del ritual quedaron en un lugar indeterminado y, en principio, alejado del lugar del depósito.

Este último depósito de los restos debemos entenderlo como una ceremonia post-funeral propiamente dicha, que es posible que pusiera fin a las celebraciones por la muerte del difunto. Debemos tener en cuenta también la posible existencia de rituales conmemorativos que pudieran haberse realizado en la superficie de los hoyos y/o en el túmulo de tierra que los cubría. Tenemos como posibles evidencias los fragmentos de cerámicas, huesos de fauna y otros materiales recogidos en los niveles superficiales en la excavación y también en prospección, con todas las reservas a este respecto. Además, está el indicio que supone la intensa actividad de expoliadores en este punto concreto.

En todo caso, y como conclusión importante, las evidencias nos indican que este tipo de ritual que hemos documentado e identificado, aunque sigue el esquema general de los rituales de cremación identificados en la Edad del Hierro en Europa Occidental, y más concretamente en el ámbito céltico, es claramente distinto en varios elementos. Fundamentalmente en el tratamiento de los restos y la selección de una representación de éstos (pars pro toto) para su depósito en hoyo en el espacio de necrópolis. Es evidente que la parte más importante del ritual se hace desaparecer de alguna manera, mientras la parte más pequeña, meramente conmemorativa, se preserva. En este sentido creemos que por primera vez estamos identificando dos cosas:

1- De un lado, pensamos que hemos documentado el fenómeno que se viene denominando como «tumbas invisibles» o, en otros casos, «cementerios invisibles». Este fenómeno arranca en la Edad del Bronce y resulta relativamente frecuente en la Edad del Hierro en el ámbito céltico de Europa Occidental y más concretamente en la fachada atlántica. En este tipo de ritual se ha sugerido que para la completa desaparición de los restos el único espacio en el que 
esto resulta viable es el agua, en ríos o lagos (RuizGálvez, 1982; Meijide, 1994: 218; Sopeña, 1995: 184-262; James, 2005: 99; Torres-Martínez, 2011: 527; Fernández-Götz, 2014: 233, 249). El espacio que hemos excavado funcionaría como lugar de enterramiento o de necrópolis pero, aparentemente, desde el punto de vista arqueológico no tiene el aspecto que habitualmente suele atribuirse a tal tipo de estructura ritual. En los primeros momentos de excavación nosotros mismos tuvimos la sensación de estar en una zona de basurero o una zona de acumulación de detritus hasta que pudimos identificar de forma individualizada los hoyos y sus contenidos. Estos aparecieron claramente delimitados y, algunos de ellos perfectamente sellados por cubiertas de piedras. No obstante, al excavar éstos, se puso de manifiesto la ausencia de paquetes de restos óseos inequívocamente humanos y la ausencia de ajuares en algunos hoyos podía hacer parecer inexacto hablar de tumbas. Por este motivo fuimos conscientes de que era necesario desarrollar un profundo trabajo de investigación de los restos recuperados. Los análisis realizados posteriormente han permitido una adscripción inequívoca de los materiales recuperados, al identificar que se ha procedido a la cremación deliberada y cuidadosa de los restos humanos y de sus objetos personales. También por la identificación de huesos humanos (análisis histológico), aun con todas las dificultades que se pueden derivar de haber empleado un método novedoso y en desarrollo inicial. Debemos recalcar que todos los resultados de los distintos análisis realizados indican que se trata de un ritual de tipo funerario.

La cremación aparece como muy intensa y destructiva para los materiales, y el tratamiento posterior minimiza los restos, de por sí ya muy alterados. Además, apenas se recoge prácticamente nada de ellos preservándose una muy pequeña parte de los restos humanos y de los ajuares y porciones de animales que acompañaban al cadáver en la cremación. Esta misma práctica se documenta en el Bernorio ya en fechas del cambio entre la Primera y la Segunda Edad del Hierro si atendemos a las cronologías dadas a los elementos que integran los ajuares recuperados en 1890 y 1944 , en especial los puñales Monte Bernorio. J. San Valero (1944: 28-33, 45-47), cuando excava en la necrópolis, alude expresamente a la ausencia aparente de restos óseos humanos identificables y, en general, a la escasez de restos óseos: un par de esquirlas. Por tanto, se trata de una práctica que presenta una larga duración, y que estuvo en uso al menos varios siglos, atendiendo a la datación de los materiales, por un lado, y a las fechas radiocarbónicas que tenemos disponibles por el otro.

2- La caracterización de un tipo de ritual que estaba pasando inadvertido, en el que los restos que quedan depositados en el espacio de necrópolis no son tanto los del difunto (o una parte más o menos importante del difunto) sino del ritual en sí. No se conmemora tanto al muerto como al ritual del funeral, que es más un hecho social colectivo que una conmemoración individual del muerto. Y esto es una diferencia importante con respecto a otros tipos de rituales de cremación identificados en otros tipos de necrópolis.

$\mathrm{Si}$, como pensamos, hemos identificado el tipo de ritual que genera la invisibilidad de un determinado tipo de fenómeno funerario, con cremación y desaparición de la mayor parte de los restos, creemos que hemos dado un importante paso adelante en la solución de este problema. Sin embargo, no podemos dedicarnos en este trabajo a desarrollar una discusión extensa sobre este tipo de fenómeno. Pero creemos que debemos someter esto a la discusión de la comunidad de especialistas, exponiendo, como hemos hecho, con detalle y de un modo preciso las evidencias que nos permiten afirmar esto.

No resulta menos importante la constatación de un proceso de adopción de elementos propios del equipamiento militar romano. Esto parece lógico dado lo prolongado del enfrentamiento entre los Pueblos del Norte de la Península Ibérica y los romanos. Así mismo, los romanos también adoptaron elementos militares propios de los celtas hispanos. La presencia de elementos característicos de la indumentaria militar romana como la fíbula de tipo Alesia o las tachuelas de caliga nos estaría indicando, tanto la toma de trofeos, como la apropiación de objetos de este tipo como propios, pero se constata que este proceso se está produciendo varias décadas antes de la conquista romana del territorio. Esto se produjo probablemente por la participación en enfrentamientos armados tanto como aliados (en conflictos internos romanos), como mercenarios o como enemigos en las décadas previas a las Guerras Cántabras (Peralta, 2003: 184-188, 210-211, 299-319; Torres-Martínez, 2011: 432-433，439-442). Este tipo de evidencias demuestra la importancia que la guerra y todo lo relacionado con los enfrentamientos armados tuvieron en este convulso periodo de la Historia del continente europeo.

De otro lado, la presencia de pequeños fragmentos de recipientes de cerámica de tipo terra sigillata en contextos rituales funerarios en fechas anteriores a la conquista romana indica el acceso a intercambios de tipo comercial o diplomático. Está el problema de que las fechas radiocarbónicas obtenidas indicarían unas fechas demasiado tempranas para la llegada de este tipo de cerámica al ámbito del Cantábrico. Pero es plausible que la terra sigillata hubiera llegado al final de la década de los años 30, fecha que se admite como de inicio de las producciones de sigillata en Italia (Van Oyen, 2015: 281-287). En todo caso, se podría admitir que estas cerámicas llegaran tan solo unos años antes (pocos) de las Guerras Cántabras y que están presentes en la necrópolis dentro de este margen de tiempo, justo antes del inicio del conflicto. 


\section{CONCLUSIONES}

En este trabajo hemos realizado un análisis de la evolución de los modos de intervención y de los puntos de interés de la arqueología funeraria en el cantábrico desde finales del siglo XIX hasta la actualidad. Si en el inicio el interés era meramente el coleccionismo erudito y anticuarista, y en la mitad del siglo XX primaban las cuestiones relativas a los ajuares con elementos metálicos y su clasificación, actualmente nuestro interés científico sigue otras líneas. En este sentido, nuestro trabajo se ha centrado en la obtención de información a partir de las oportunidades que permiten las nuevas tecnologías aplicadas a la analítica de evidencias arqueológicas. Pero este empleo de la tecnología no es un fin en sí mismo, sino que busca la generación de datos e información para permitir una mejor interpretación del registro arqueológico y la obtención de nuevas formas de conocimiento. El volumen creciente de datos que podemos obtener debe ser interpretado por arqueólogos cualificados con un suficiente conocimiento de su medio profesional en la más vasta acepción de este término. En este sentido se trata de generar discurso histórico desde una posición propia de las Ciencias Sociales, con un enfoque que busca explícitamente la obtención de la mayor cantidad posible de elementos empíricos desde los que generar conocimiento. Obtener mucha menos especulación y muchas más evidencias, información y conocimiento.

La planificación de la intervención ha resultado esencial para la recogida cuidadosa de todo tipo de evidencias, en especial de aquellas que varias décadas atrás resultaban prácticamente invisibles o inviables. Esto ha permitido la obtención de un volumen considerable de restos de los que ha sido posible obtener una gran cantidad de datos útiles, pese a todas las limitaciones propias de trabajar con unos reducidísimos recursos económicos y con dificultades de todo tipo. Con esta información ha sido posible convertir en útiles evidencias que antes se perdían por la inviabilidad de sus análisis. De este modo, hemos podido recrear a través de evidencias un tipo de ritual que, aunque podíamos intuir, hasta ahora resultaba completamente desconocido en los elementos que lo componían y en los distintos procesos que implicaba.

La recogida cuidadosa de todo tipo de contenidos y de muestras es lo que permite un análisis minucioso de restos y la obtención de este volumen de información impensable hasta fechas muy recientes. Los análisis de fauna, de tierras, de cenizas y de huesos cremados, aun sin agotar completamente sus posibilidades, nos muestran un amplio campo para la investigación de rituales efímeros y con un reducido índice de conservación. Rituales sobre los que las fuentes grecolatinas apenas aportan información útil.

Se demuestra que, para la identificación de restos óseos humanos, en este tipo de contextos arqueológicos y con este tipo de rituales, el único procedimiento viable es la realización de un análisis histológico. Este procedimiento, actualmente experimental y en vías de desarrollo, creemos puede ser una vía de identificación válida una vez se mejoren dichos métodos de identificación en huesos alterados por cremación a altas temperaturas.

Las fechas radiocarbónicas señalan a esta necrópolis céltica prerromana, por el momento, probablemente como la más tardía en uso en el occidente de Europa continental, lo que creemos que resulta de enorme interés para el estudio de las últimas sociedades celticas del continente (Torres-Martínez, 2011: 514-541). Queda establecido que se trata de un sector de la necrópolis en uso en el periodo final de vida del oppidum, entre finales del siglo II a.C. y las décadas previas al ataque romano a finales del siglo I a.C., con algunos materiales que señalan también a los años anteriores al 26 a. C. Es el caso de los fragmentos de terra sigillata y la fíbula Alesia, que apuntan en esta dirección. Se constatan los procesos de aculturación de estas sociedades en su intenso contacto con el imperio romano, lo que no fue óbice para que plantearan una férrea resistencia militar a la conquista romana cuyas pruebas están también presentes en este mismo yacimiento, incluso en los niveles más superficiales de estas estructuras funerarias (Torres-Martínez, Serna y Domínguez, 2011; Torres-Martínez, Martínez y Pérez, 2012; 2013; Camino et al., 2015).

\section{REFERENCIAS}

Alcántara, V., Barba, R., Barral, J., Crespo, A., Eiriz, A., Falquina, A. y Domínguez-Rodrigo, M. (2006). Determinación de procesos de factura sobre huesos frescos: Un sistema de análisis de los ángulos de los planos de fracturación como discriminación de agentes bióticos. Trabajos de Prehistoria, 63(1), 37-45. DOI: http://dx.doi.org/10.3989/tp.2006.v63. i1.3

Alonso, J., Cerdán, R. y Filloy, I. (1999). Nuevas Técnicas Metalúrgicas en armas de la II Edad del Hierro. Arqueometalúrgia y Conservación Analítica en la Necrópolis de La Hoya Laguardia, Álava. Vitoria: Diputación Foral de Álava.

Barone, R. (1990). Anatomía comparada de los mamíferos domésticos. Tomo I y Parte II. Buenos Aires: Hemisferio Sur.

Barril Vicente, M. (1995a). El Castro de Los Barahones Valdegama, Palencia: Un Poblado en el Alto Valle del Pisuerga. En III Simposio Sobre Los Celtíberos. Poblamiento Celtibérico (pp. 399-408). Zaragoza: Institución Fernando el Católico.

Barril Vicente, M. (1995b). Comentarios sobre el fondo de cabaña de Monte Bernorio. En Actas del III Congreso de Historia de Palencia (pp. 153-173). Palencia: Diputación Provincial de Palencia.

Barril Vicente, M. (1999). Dos yacimientos de la Edad del Hierro, Castro de Los Barahones y Bernorio. En Regio Cantabrorum (pp. 43-52). Santander: Caja Cantabria. 
Buora, M. (2005). Osservazioni sulle fibule del tipo Alesia nell'arco alpino orientale e nell'alto Adriatico. Vjesnik za arheologiju i historiju dalmatinsku, 98, 83-91.

Cabré Aguiló, J. (1920). Acrópoli y necrópoli cántabras de los Celtas Berones del Monte Bernorio. Sociedad Española de Amigos del Arte, 34, 5-34.

Cabré Aguiló, J. y Cabré Herreros, M. E. (1933). Datos para la cronología del puñal de la cultura cogotas. Archivo Español de Arte y Arqueología, IX, 37-45.

Cabré de Morán, M. E. y Baquedano, M. I. (1997). El armamento céltico de la Segunda Edad del Hierro. En La Guerra en la Antigüedad. Una aproximación al origen de los ejércitos en Hispania (pp. 240-259). Madrid: Fundación Caja de Madrid.

Camino, J., Peralta, E. y Torres-Martínez, J. F. (Coords.). (2015). Las Guerras Ástur-cántabras. Gijón: KRK Ediciones.

Castrogiovanni, P., Imbesi, R., Fisichella, M. y Mazzone V. (2011). Osteonic organization of limb bones in mammals, including humans, and birds: a preliminary study. Italian Journal of Anatomy and Embriology, 116, 30-37. DOI: http://dx.doi.org/10.13128/IJAE-8788

Demetz, S. (1999). Fibeln der spätlatène - und frühen römischen Kaiserzeit in den Alpenländern. Frühgeschichtlichen und Provinzialrömische Archäologie, Materialien und Forschungen, vol. 4. Rahden: Leidorf.

Erice Lacabe, R. (1995). Las fibulas del nordeste de la Península Ibérica: siglos I. a.e. al IV d.e. Zaragoza: Institución Fernándo el Católico.

Fábregas, R. y Bradley, R. (1995). El silencio de las fuentes: prácticas funerarias en la Edad del Bronce del Noroeste y su contexto europeo. Complutum, 6, 153-166.

Fernández-Götz, M. (2014). De la Familia a la Etnia. Protohistoria de la Galia Oriental. Bibliotheca Archaeologica Hispana, 41. Madrid: Real Academia de la Historia.

Filloy Nieva, I. (2000). The Miraveche-Monte Bernorio type daggers: new data about their manufacture. Re-enactments as research. Journal of Roman Military Equipment Studies, 11, 11-16.

García Guinea, M. A., González Echegaray, J. y San Miguel Ruiz, J. A. (1966). Excavaciones en Monte Cildá. Olleros de Pisuerga Palencia 1963-1965. Excavaciones Arqueológicas en España, 61. Palencia: Diputación de Palencia.

Greenfield, H. J. (1988). Bone consumption by pigs in a contemporary Serbian village: implications for the interpretation of prehistoric faunal assemblages. Journal of Field Archaeology, 15, 473-479. DOI: http://dx.doi.org/10.1179/ jfa.1988.15.4.473

Griñó Frontera, B. de (1987). Los puñales de tipo Monte Bernorio-Miraveche. Zephyrus, 39-40, 297-306.

Griñó Frontera, B. de (1989a): Los Puñales de tipo Mte. Bernorio-Miraveche. Un arma de la Segunda Edad del Hierro en la Cuenca del Duero. Texto. BAR International Series, 504 i. Oxford: British Archaeological Reports.
Griñó Frontera, B. de (1989b). Los Puñales de tipo Mte. Bernorio-Miraveche. Un arma de la Segunda Edad del Hierro en la Cuenca del Duero. Figuras y Láminas. BAR International Series, 504 ii. Oxford: British Archaeological Reports.

Halstead, P. y Collis, P. (2002). Sorting the Sheep from the Goats: Morphological Distinctions between the Mandibles and Mandibular Teeth of Adult Ovis and Capra. Journal of Archaeological Science, 29, 545-553. DOI: http://doi. org/10.1111/j.1556-4029.2006.00368.x

Hillier M. y Bell L. (2007). Differentiating human bone from animal bone: a review of histological methods. Journal of Forensic Science, 52(2), 249-263.

Hillson, S. (2005). Teeth. Cambridge: Cambridge University Press.

James, S. (2005). El mundo de los celtas. Nuevo y contrastado estudio sobre la Historia y la Cultura de los Celtas. Barcelona: Blume.

Leroi-Gourham, A. (1971). El Gesto y la Palabra. Caracas: Universidad Central de Venezuela.

Mariezkurrena, K. (2004). Talla del bovino en el País Vasco durante la Edad del Hierro y las épocas romana y medieval. Munibe, 56, 79-86.

Mariezkurrena, K. y Altuna, J. (1983). Biometría y dimorfismo sexual de «Cervus Elaphus» würmiense, postwürmiense y actual del Cantábrico. Munibe, 35, 203-246.

Meijide Cameselle, G. (1994). El concepto de las relaciones atlánticas en la Edad del Bronce del Noroeste. En S. Reboreda y L. Castro (Coords.). Edad del Bronce (pp. 195-232). Vigo: Universidad de Vigo.

Moro, R. (1891). Exploraciones Arqueológicas. Monte Cildá. Monte Bernorio. Loncejares. Arconada. Boletín de la Real Academia de la Historia, XVIII, 427-440.

Navarro García, R. (1939). Catálogo Monumental de la Provincia de Palencia. Fascículo Tercero. Partidos de Cervera del Río Pisuerga y Saldaña. Palencia: Diputación Provincial de Palencia.

Nickel, R., Schummer, A. y Seiferle, E. (1977). Anatomy of the Domestic Birds. Berlin-Hamburg: Springer-Verlag.

Peralta Labrador, E. (2003). Los Cántabros antes de Roma. Bibliotheca Archaeologica Hispana, 5. Madrid: Real Academia de la Historia.

Prummel, W. y Frisch, H-J. (1986). A Guide for the Distinction of Species, Sex and Body Side in Bones of Sheep and Goat. Journal of Archaeological Science, 13, 567-577. DOI: https://doi.org/10.1016/0305-4403(86)90041-5

Quesada Sanz, F. (2004). La alzada del caballo antiguo: un estado de la cuestión aplicado a la Edad del Hierro en la Península Ibérica. Cuadernos de Prehistoria y Arqueología de la Universidad Autónoma de Madrid, 30, 77-89.

Ramalho S. A., Daruge E., Cruz V. de la, Francesquini, M. A., Pereira S., Francesquini Junior L., y Ambrosano G. (2003). La importancia pericial del estudio comparativo 
histomorfológico del hueso humano y de otros géneros. Revista de la Asociación Dental Mexicana, LX(5), 173-186.

Ramsey, C.B. (2001): Development of the Radiocarbon calibration program OxCal. Radiocarbon, 43, 355-363.

Reimer, P. J., Bard, E., Bayliss, A., Beck, J. W., Blackwell, P. G., Ramsey, C. B., y van der Plicht, J. (2013). IntCal13 and Marine13 Radiocarbon Age Calibration Curves 0-50,000 Years cal BP. Radiocarbon, 55(4), 1869-1887.

Ruiz-Gálvez Priego, M. (1982). Nueva espada dragada en el río Ulla. Armas arrojadas a las aguas. El Museo de Pontevedra, XXXVI, 181-196.

San Valero Aparisi, J. (1944). Excavaciones Arqueológicas en Monte Bernorio Palencia. Primera Campaña, 1943. Informes y Memorias, 5. Madrid: Ministerio de Educación Nacional.

San Valero Aparisi, J. (1960). Monte Bernorio. Aguilar de Campoo Palencia. Campaña de Estudio en 1959. Excavaciones Arqueológicas en España, 44. Madrid: Ministerio de Educación Nacional.

Sanz Mínguez, C. (1986). Variantes del puñal de tipo Monte Bernorio en el valle medio del Duero. Boletín del Seminario de Estudios de Arte y Arqueología, LII, 25-46.

Sanz Mínguez, C. (1990). Metalistería prerromana en la cuenca del Duero. Una propuesta secuencial para los puñales de tipo Monte Bernorio. Boletín del Seminario de Estudios de Arte y Arqueología, LVI, 170-188.

Sanz Mínguez, C. (1997). Los Vacceos: cultura y ritos funerarios de un pueblo prerromano del valle medio del Duero. La necrópolis de las Ruedas, Padilla del Duero Valladolid. Arqueología en Castilla y León, Memorias, 6. Valladolid: Universidad de Valladolid.

Sanz Mínguez, C. y Escudero Navarro, Z. y Fontaneda Berthet, C. (1991). Tres piezas de metalistería prerromana en la Colección Fontaneda (castillo de Ampudia, Palencia). Boletín del Seminario de Arte y Arqueología, LXII, 79-93.

Schmid, E. (1972). Atlas of Animal Bones. For Prehistorians, Archaeologists, and Quaternary Geologists. New York: Elsevier

Schüle, W. (1969a). Die Meseta-Kulturen der Iberischen Halbinsel. Text und Kataloge. Mediterrane und Eurasische elemente in Früheisenzeitlichen Kulturen Südwesteuropas. Berlin: Walter de Gruyter.

Schüle, W. (1969b). Die Meseta-Kulturen der Iberischen Halbinsel. Karten und Tafeln. Mediterrane und Eurasische elemente in Früheisenzeitlichen Kulturen Südwesteuropas. Berlin: Walter de Gruyter.

Sisson, S. y Grossman, J. D. (1982). Anatomía de los animales domésticos, Tomo II. Barcelona: Salvat.

Sopeña Genzor, G. (1995). Etica y Ritual. Aproximación al estudio de la religiosidad de los pueblos celtibéricos. Zaragoza: Universidad de Zaragoza.

Torres-Martínez, J. F. K. (2011). El cantábrico en la Edad del Hierro. Medioambiente, economía, territorio y sociedad.
Bibliotheca Archaeologica Hispana, 35. Madrid: Real Academia de la Historia.

Torres-Martínez, J. F. K. (2015). El ataque a Monte Bernorio Villarén, Pomar de Valdivia, Palencia. En J. Camino, E. Peralta y J.F. Torres-Martínez (Coords.) Las Guerras Ásturcántabras (pp. 111-130). Gijón: KRK Ediciones.

Torres-Martínez, J. F. K., Ballester, X., Fernández, C., Montero, I. y Martín, R. (2013). Sobre la Tessera de Hospitalidad del oppidum de Monte Bernorio Palencia. Un excepcional documento en bronce de la $\mathrm{II}^{\mathrm{a}}$ Edad del Hierro. Avance a su interpretación, análisis y conservación. Sautuola, XVIII, 115-132.

Torres-Martínez, J. F. K., Domínguez, S. D. y Carnicero, S. (2012). Inhumaciones de perinatales en el área de la muralla sur del oppidum de Monte Bernorio Villarén, Palencia. Ritos de edad y rituales funerarios. Munibe, 63, 199-211.

Torres-Martínez, J. F. K., Fernández-Götz, M. y Sobremazas, J. M. (2016). Los nombres del Oppidum de Monte Bernorio Villarén, Palencia. Las denominaciones de los Oppida Célticos del norte de la península ibérica: estructura política e identidad étnica. Onoba, 4, 163-180.

Torres-Martínez, J. F. K., Fernández-Götz, M., Martínez, A., Vacas, D. y Rodríguez, E. (2016a). From the Bronze Age to the Roman Conquest: The Oppidum of Monte Bernorio Northern Spain. Proceedings of the Prehistoric Society, 82, 363-382. DOI: https://doi.org/10.1017/ppr.2016.11

Torres-Martínez, J. F. K., Fernández-Götz, M., Teichner, F., Martínez, A., Vacas, D. y Luis, S. de. (2016b). El oppidum de Monte Bernorio Palencia. Resultados de las campañas arqueológicas de 2004-2014. Madrider Mitteilungen, 57, 246-272.

Torres-Martínez, J. F. K., Martínez, A. y Luis, S. de. (2012). El oppidum de Monte Bernorio en la Cantabria histórica. Nueve siglos de historia. Kobie (Paleoantropología), 31, 137-156.

Torres-Martínez, J. F. K., Martínez, A. y Luis, S. de. (2013). Cuentas de pasta vítrea en el oppidum de Monte Bernorio Villarén, Palencia. Relaciones comerciales en el cantábrico en la Edad del Hierro. Sautuola, XVIII, 133-148.

Torres-Martínez, J. F. K., Martínez, A. y Luis, S. de. (2016). Les perles en pâte de verre de l'oppidum de Monte Bernorio Villarén, Palencia et du nord de la Péninsule Ibérique. Echanges et relations entre le nord de l'Espagne et le sud de la France à L'âge du Fer. Aquitania, 32, 35-57.

Torres-Martínez, J. F. K., Martínez, A. y Pérez, D. (2012). Augustan campaigns in the initial phase of the Cantabrian war and roman artillery projectiles from the Monte Bernorio oppidum Villarén, Palencia. Archaeologisches Korrespondenzblatt, 42(4), 525-542.

Torres-Martínez, J. F. K., Martínez, A. y Pérez, D. (2013). Los proyectiles de artillería romana en el oppidum de Monte Bernorio Villarén, Palencia y las campañas de Augusto en la primera fase de la guerra cantábrica. Gladius, 33, 57-80. DOI: https://doi.org/10.3989/gladius.2013.0003 
Torres-Martínez, J. F. K., Martínez, A. y Serna, A. (2013). El oppidum de Monte Bernorio Villarén, Palencia. Una ciudad fortificada de la Edad del Hierro en la Montaña Palentina. Colección de Historia de la Montaña Palentina, 7, 11-86.

Torres-Martínez, J. F. K., Martínez, A. y Vacas, D. (2015). El oppidum de Monte Bernorio, estructura defensiva y proyección territorial. En. O. Rodríguez, R. Portilla, J. C. Sastre, y P. Fuentes (Coords.). Fortificaciones en la Edad del Hierro: control de los recursos y el territorio (pp. 109-128). Zamora: Glyphos.

Torres-Martínez, J. F. K., Serna, A. y Domínguez, S. D. (2011). El ataque y destrucción del oppidum de Monte Bernorio Villarén, Palencia y el establecimiento del castellum romano. Habis, 42, 127-151.

Torres-Martínez, J. F. K., Teichner, F., Fernández-Götz, M. y Vallés, J. (2016). Resultados de las Prospecciones Geomagnéticas desarrolladas en el Oppidum de Monte Bernorio
Pomar de Valdivia, Palencia. Trabajos de Prehistoria, 73(2), 365-376. DOI: http://doi.org/10.3989/tp.2016.12180

Van Klinken, G.J. (1999). Bone collagen quality indicators for palaeodietary and radiocarbon measurements. Journal of Archaeological Science, 26(6), 687-695.

Van Oyen, A. (2015). The roman city as articulated through terra sigillata. Oxford Journal of Archaeology, 34(3), 279-299.

Varela, S. y Rodríguez, J. (2004). Carnívoros Ibéricos. Madrid: Colegio Oficial de Biólogos.

Vázquez, J. Ma et al. (1995). Cuadernos Prácticos de Osteología Veterinaria. Volumen II: Rumiantes y Suidos. Vaca, cabra y oveja y cedro. Murcia: Servicio de Publicaciones de la Universidad de Murcia.

Yravedra, J. (2006). Tafonomía aplicada a Zooarqueología. Madrid: UNED Ediciones. 